\title{
Article \\ Quantitative Proteomic Profiling of tachyplesin I Targets in U251 Gliomaspheres
}

\author{
Xuan $\mathrm{Li}^{\dagger}$, Jianguo Dai ${ }^{\dagger}$, Yongjun Tang, Lulu Li and Gang Jin * \\ School of Applied Chemistry and Biotechnology, Shenzhen Polytechnic, No. 2190 Liuxian Road, \\ Nanshan District, Shenzhen 518055, Guangdong, China; smilelixuan@163.com (X.L.); jgdai@szpt.edu.cn (J.D.); \\ tangyongjun@szpt.edu.cn (Y.T.); lilulu011071@hotmail.com (L.L.) \\ * Correspondence: jingang@szpt.edu.cn \\ $\dagger$ These authors contributed equally to this work. \\ Academic Editor: Paul Long
}

Received: 20 November 2016; Accepted: 12 January 2017; Published: 18 January 2017

\begin{abstract}
I is a cationic peptide isolated from hemocytes of the horseshoe crab and its anti-tumor activity has been demonstrated in several tumor cells. However, there is limited information providing the global effects and mechanisms of tachyplesin I on glioblastoma multiforme (GBM). Here, by using two complementary proteomic strategies (2D-DIGE and dimethyl isotope labeling-based shotgun proteomics), we explored the effect of tachyplesin I on the proteome of gliomaspheres, a three-dimensional growth model formed by a GBM cell line U251. In total, the expression levels of 192 proteins were found to be significantly altered by tachyplesin I treatment. Gene ontology (GO) analysis revealed that many of them were cytoskeleton proteins and lysosomal acid hydrolases, and the mostly altered biological process was related to cellular metabolism, especially glycolysis. Moreover, we built protein-protein interaction network of these proteins and suggested the important role of DNA topoisomerase 2-alpha (TOP2A) in the signal-transduction cascade of tachyplesin I. In conclusion, we propose that tachyplesin I might down-regulate cathepsins in lysosomes and up-regulate TOP2A to inhibit migration and promote apoptosis in glioma, thus contribute to its anti-tumor function. Our results suggest tachyplesin I is a potential candidate for treatment of glioma.
\end{abstract}

Keywords: tachyplesin I; glioblastoma multiforme; cancer stem cell; stable isotope dimethyl labeling; parallel reaction monitoring

\section{Introduction}

Gliomas, the most common group of primary brain tumors, are subcategorized into astrocytomas, oligodendrogliomas and ependymomas. According to World Health Organization (WHO), glioblastoma multiforme (GBM), the most malignant and lethal form of brain tumor in adults, is a grade IV astrocytoma with very high morbidity and mortality. The disease has a very poor prognosis with short median survival, only about 15 months, despite current multimodal treatment including maximal surgical resection if feasible, followed by a combination of radiotherapy and/or chemotherapy [1]. Therefore, it is imperative to present new and more effective therapeutic interventions to better control GBM.

In fact, the short median survival of GBM is largely ascribed to the inevitable tumor recurrence. Recent research has paid more attention to the existence of glioma stem cells (GSCs), which are a subgroup of tumor cells with properties that resemble those of neural stem cells, and are able to drive tumorigenesis and likely contribute to rapid tumor recurrence [2]. These cells were first described more than ten years ago and have been demonstrated with the capability of multi-lineage differentiation, self-renewal and extensive proliferation [3]. In addition, GSCs can endure and even thrive in stressful 
tumor conditions, including hypoxia, oxidative stress, inflammation, acidic stress, and low glucose [4]. Moreover, their resistance to conventional therapy and promotion of tumor angiogenesis also influence clinical practice $[5,6]$. Thus, GSCs provide new insight into the strategy in GBM therapy.

Three-dimensional growth model, a growth sphere formed by cancer stem cells under specific culture conditions in vitro, is a more reasonable model for tumor biology and drug screening in vitro studies $[7,8]$. Likewise, GSCs also have the characteristic of forming spheres and clinical data show that the rates of existence of gliomaspheres were more prominent in high grade malignant gliomas [9]. Previously, we isolated gliomaspheres from U251 glioma cell lines and tried to apply it for drug screening. We found that there were undifferentiated GSCs and differentiated cancer cells with different differentiation degrees in gliomaspheres, which were similar to the growth state of glioma in vivo [10]. Our previous data showed that gliomaspheres express stem cell biomarkers nestin and CD133, which are certain phenotypes of GSC, and tachyplesin I inhibited the viability and proliferation of gliomaspheres dose dependently, by damaging the plasma membrane and inducing differentiation of GSCs [11]. These findings indicate that tachyplesin I is a potential anti-tumor drug which may be used in GBM therapy.

tachyplesin I, a cationic peptide with 17 residues $\left(\mathrm{NH}_{2}-\mathrm{K}-\mathrm{W}-\mathrm{C}-\mathrm{F}-\mathrm{R}-\mathrm{V}-\mathrm{C}-\mathrm{Y}-\mathrm{R}-\mathrm{G}-\mathrm{I}-\mathrm{C}-\mathrm{Y}-\mathrm{I}-\mathrm{R}-\mathrm{R}-\mathrm{C}-\mathrm{R}\right.$ $-\mathrm{CONH}_{2}$ ), was originally isolated from hemocytes of the horseshoe crab (Tachypleus tridentatus) [12]. It has the ability of anti-enzymatic hydrolysis due to two disulfide-stabilized $\beta$-hairpins [13]. Several studies have demonstrated that tachyplesin I can inhibit the proliferation and affect the differentiation of tumor cells, such as hepatocarcinoma, gastric adenocarcinoma and leukemia $[14,15]$. This peptide has also been demonstrated to activate the classic complement pathway to lyse and kill tumor cells and to alter the expression of tumor suppressor genes and oncogenes to induce cell differentiation and reverse the malignant phenotype [16,17]. Most interestingly, the negatively charged components of cancer cells, which are quite different from neutral normal cells, are more vulnerable by the positively charged cationic peptides, including tachyplesin I. The electrostatic attraction between cancer cells and cationic peptides is believed to play a major role in the selective disruption of cancer cell membranes, which avoids traditional mechanism of drug resistance [18].

Although the anti-tumor effect of tachyplesin I has been studied to some extent, the mechanism of anti-tumor activity in GBM is largely unknown. In recent years, proteomics has been shown to be a powerful approach for exploring the molecular mechanisms of anti-tumor drugs. In this study, our primary goal was to identify the changes in protein expression profile of U251 gliomaspheres under the treatment of tachyplesin I, which may help us to better understand the molecular mechanisms underlying potential anti-glioma drugs. Here, both gel-based and shotgun proteomic approaches were performed to gain a higher proteome coverage and better quantification results [19]. Proteomic analysis using two dimension difference gel electrophoresis (2D-DIGE) and stable isotope dimethyl labeling based Liquid chromatography-mass spectrometry/mass spectrometry (LC-MS/MS) revealed that 192 proteins were differentially expressed in U251 gliomaspheres in response to tachyplesin I. Biological involvement of these proteins are further discussed in detail through signaling pathways and protein-protein interaction network analysis. Furthermore, the expression of cathepsins in lysosomes and TOP2A was further validated by Western blot and PRM, due to their important involvement in the anti-tumor activity of tachyplesin I, by inhibiting migration and promote apoptosis of glioma cells, respectively.

\section{Results}

\subsection{Protein Expression Profile of tachyplesin I Treated U251 Gliomaspheres Using 2D-DIGE Analysis}

The 2D-DIGE images, which were scanned at the wavelengths of 488/520, 532/580, and 633/ $670 \mathrm{~nm}$, visualize the protein expression pattern in the cells (Figure 1A). In the image analysis, 1298 protein spots were detected. Of these, 35 spots with fold change larger than \pm 1.5 were considered significantly altered in tachyplesin I treated U251 gliomaspheres compared with untreated control 
(Figure 1B). Among the protein spots that satisfied the statistical criteria, 26 were confidently identified by MALDI-TOF/TOF analysis. Out of 26 identified proteins, 13 were up-regulated while the others were down-regulated in tachyplesin I treated U251 gliomaspheres. Up-regulated proteins were mainly involved in regulation of cell cycle and apoptosis, and cytoskeleton proteins (Table 1). Conversely, down-regulated proteins were involved in glycolysis, response to stimulus and calcium or ion binding (Table 1). Several proteins (Vimentin, Phosphate carrier protein, mitochondrial and Guanine nucleotide-binding protein $\mathrm{G}(\mathrm{q})$ subunit alpha) were identified more than once in different location of 2D-DIGE gel, suggesting diverse protein isoforms, such as the occurrence of post-translational modification. Representative images of one up-regulated protein endothelin-converting enzyme 1 (ECE1) and one down-regulated protein alpha-enolase (ENO1) in different dose groups are shown in Figure 1C. Western blot assay was performed to confirm the results obtained from 2D-DIGE experiment and the results were consistent (Figure 1C).

A

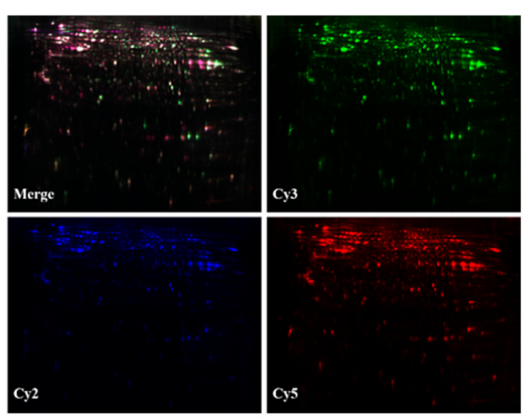

C

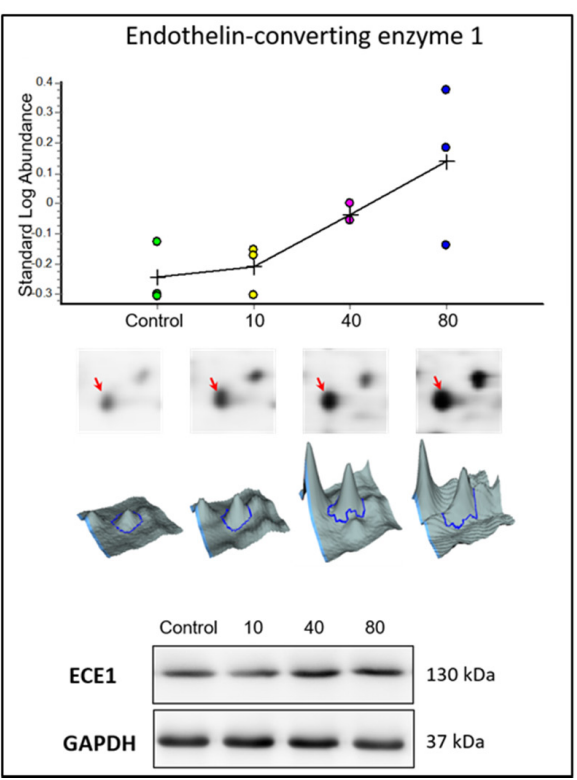

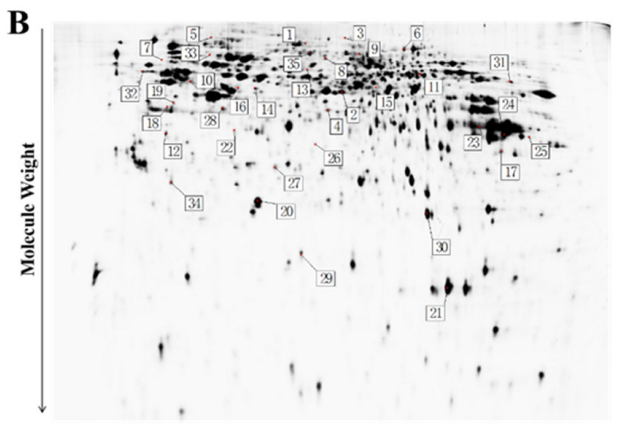

pH 3

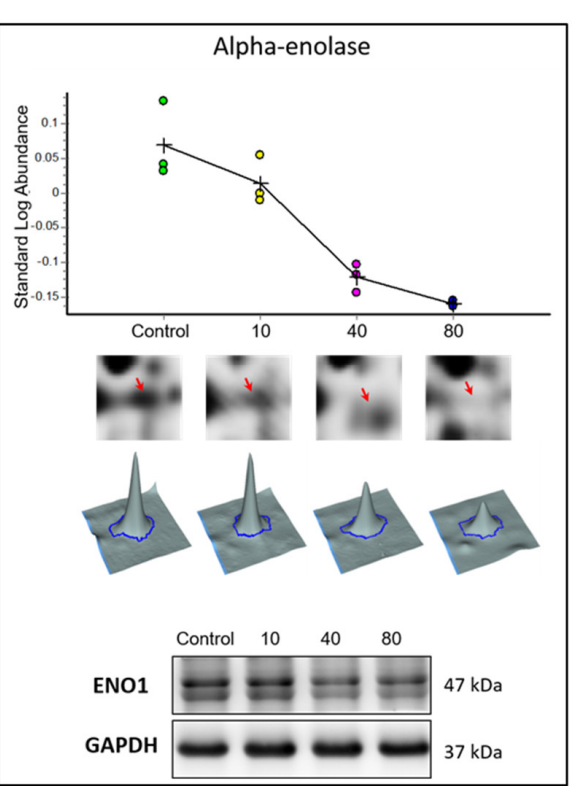

Figure 1. Two dimension difference gel electrophoresis (2D-DIGE) analysis of U251 gliomaspheres after treated with tachyplesin I. (A) Representative scanned 2D-DIGE images of Cy2, Cy3, and Cy5, and their overlay derived from a single gel; (B) Representative 2D-DIGE protein profiles with the protein spots marked as differentially regulated in U251 gliomaspheres treated with tachyplesin I. Information about the proteins corresponding to the spot numbers is listed in Table 1; (C) The expression levels of endothelin-converting enzyme 1 (ECE1) and alpha-enolase (ENO1) in U251 gliomaspheres treated by $0,10,40 \mathrm{and} 80 \mathrm{\mu g} / \mathrm{mL}$ of tachyplesin I for $24 \mathrm{~h}$ are visualized by protein abundance maps (first panel), 2-DE images (second panel), three-dimensional spot images (third panel) and validated by Western blot (bottom panel). GAPDH was used as a loading control. 
Table 1. Regulated proteins of tachyplesin I treated U251 gliomaspheres in the 2D-DIGE study.

\begin{tabular}{|c|c|c|c|c|c|c|c|c|c|}
\hline \multicolumn{10}{|c|}{ Up-Regulated Proteins of tachyplesin I Treated U251 Gliomaspheres in the 2D-DIGE Study } \\
\hline \multirow{2}{*}{ No. ${ }^{a}$} & \multirow{2}{*}{ Gene Name } & \multirow{2}{*}{ Uniprot ID } & \multirow{2}{*}{ Protein Name } & \multirow{2}{*}{ Mascot Score } & \multirow{2}{*}{ Peptides } & \multirow{2}{*}{ Protein MW } & \multirow{2}{*}{ pI Value } & \multirow{2}{*}{$\begin{array}{c}\text { Ratio } / p \text { Value }{ }^{\mathrm{b}} \\
10 \text { vs. } 0^{\mathrm{c}}\end{array}$} & \multirow{2}{*}{$\begin{array}{c}\text { Ratio/p Value } \\
40 \text { vs. } 0^{\mathrm{c}}\end{array}$} \\
\hline & & & & & & & & & \\
\hline \multicolumn{10}{|c|}{ Regulation of cell cycle or apoptosis ${ }^{\mathrm{d}}$} \\
\hline 2 & PHGDH & O43175 & D-3-phosphoglycerate dehydrogenase & 104 & 3 & 57,356 & 6.3 & $1.54 / 0.003$ & $1.69 / 0.017$ \\
\hline 5 & MSH2 & P43246 & DNA mismatch repair protein Msh2 & 93 & 2 & 104,743 & 5.8 & $1.21 / 0.009$ & $1.77 / 0.035$ \\
\hline 19 & SESN3 & P58005 & Sestrin-3 & 201 & 4 & 57,291 & 6.3 & $1.52 / 0.036$ & $2.01 / 0.027$ \\
\hline 31 & CKAP2 & Q8WWK9 & Cytoskeleton-associated protein 2 & 76 & 7 & 76,987 & 9.4 & $\mathrm{ND}^{\mathrm{e}}$ & $1.52 / 0.039$ \\
\hline 35 & ECE1 & P42892 & Endothelin-converting enzyme 1 & 46 & 1 & 87,164 & 5.9 & $1.58 / 0.038$ & $3.31 / 0.026$ \\
\hline \multicolumn{10}{|c|}{ Cytoskeletal protein ${ }^{\mathrm{d}}$} \\
\hline 3 & VIM & P08670 & Vimentin & 407 & 12 & 53,676 & 4.9 & ND & $1.64 / 0.022$ \\
\hline 4 & EEF1G & P26641 & Elongation factor 1-gamma & 47 & 2 & 50,429 & 6.3 & ND & $1.51 / 0.005$ \\
\hline 9 & EZR & P15311 & Ezrin & 168 & 3 & 69,484 & 5.9 & $1.03 / 0.024$ & $1.63 / 0.046$ \\
\hline 10 & VIM & P08670 & Vimentin & 524 & 15 & 53,676 & 4.9 & ND & $1.58 / 0.041$ \\
\hline \multicolumn{10}{|c|}{ Protein biosynthesis ${ }^{\mathrm{d}}$} \\
\hline 6 & EEF2 & P13639 & Elongation factor 2 & 60 & 1 & 96,246 & 6.4 & ND & $1.55 / 0.044$ \\
\hline 21 & PPIA & P62937 & Peptidyl-prolyl cis-trans isomerase A & 195 & 16 & 18,229 & 9 & $1.26 / 0.017$ & $1.52 / 0.028$ \\
\hline \multicolumn{10}{|c|}{ Transport $^{\mathrm{d}}$} \\
\hline 23 & SLC25A3 & F8VVM2 & Phosphate carrier protein, mitochondrial & 90 & 5 & 36,161 & 9.3 & ND & $1.72 / 0.034$ \\
\hline 25 & SLC25A3 & F8VVM2 & Phosphate carrier protein, mitochondrial & 183 & 9 & 36,161 & 9.3 & ND & $1.63 / 0.016$ \\
\hline \multicolumn{10}{|c|}{ Down-Regulated Proteins of tachyplesin I Treated U251 Gliomaspheres in the 2D-DIGE Study } \\
\hline \multicolumn{10}{|c|}{ Calcium or iron ion binding protein ${ }^{\mathrm{d}}$} \\
\hline 7 & EPS15 & P42566 & Epidermal growth factor receptor substrate 15 & 109 & 5 & 98,656 & 5.1 & $\mathrm{ND}^{\mathrm{e}}$ & $-1.88 / 0.004$ \\
\hline 13 & P4HA1 & P13674 & Prolyl 4-hydroxylase subunit alpha-1 & 86 & 5 & 61,296 & 5.6 & $-1.51 / 0.007$ & $-2.37 / 0.045$ \\
\hline \multicolumn{10}{|c|}{ Regulation of cell apoptosis or proliferation ${ }^{\mathrm{d}}$} \\
\hline 12 & ANXA5 & P08758 & Annexin A5 & 273 & 13 & 35,971 & 4.8 & ND & $-1.74 / 0.033$ \\
\hline 20 & GSTP1 & P09211 & Glutathione $\mathrm{S}$-transferase $\mathrm{P}$ & 339 & 21 & 23,569 & 5.3 & ND & $-1.66 / 0.001$ \\
\hline 33 & COL4A3BP & Q9Y5P4 & Collagen type IV alpha-3-binding protein & 250 & 7 & 70,835 & 5.5 & $\mathrm{ND}$ & $-1.64 / 0.033$ \\
\hline 34 & ARHGDIA & P52565 & Rho GDP-dissociation inhibitor 1 & 236 & 16 & 23,250 & 4.9 & $-1.23 / 0.037$ & $-2.64 / 0.047$ \\
\hline \multicolumn{10}{|c|}{ Response to stimulus ${ }^{\mathrm{d}}$} \\
\hline 14 & GNAQ & P50148 & Guanine nucleotide-binding protein $\mathrm{G}(\mathrm{q})$ subunit alpha & 193 & 9 & 42,142 & 5.7 & ND & $-1.61 / 0.037$ \\
\hline 16 & GNAQ & P50148 & Guanine nucleotide-binding protein $\mathrm{G}(\mathrm{q})$ subunit alpha & 294 & 12 & 42,142 & 5.7 & ND & $-1.59 / 0.047$ \\
\hline 28 & GNAQ & P50148 & Guanine nucleotide-binding protein $\mathrm{G}(\mathrm{q})$ subunit alpha & 182 & 7 & 42,142 & 5.7 & $-1.33 / 0.028$ & $-1.53 / 0.036$ \\
\hline \multicolumn{10}{|c|}{ Glycolysis/Gluconeogenesis d } \\
\hline 15 & ENO1 & P06733 & Alpha-enolase & 40 & 3 & 47,481 & 7.7 & $-1.04 / 0.005$ & $-1.92 / 0.054$ \\
\hline 17 & PGK1 & P00558 & Phosphoglycerate kinase 1 & 209 & 7 & 44,985 & 9.2 & $-1.68 / 0.025$ & $-2.89 / 0.051$ \\
\hline 30 & TPI1 & P60174 & Triosephosphate isomerase & 375 & 15 & 31,057 & 5.6 & $-1.17 / 0.048$ & $-1.88 / 0.028$ \\
\hline \multicolumn{10}{|c|}{ Ribosomal protein ${ }^{\mathrm{d}}$} \\
\hline 18 & RPSA & P08865 & $40 \mathrm{~S}$ ribosomal protein $\mathrm{SA}$ & 171 & 9 & 32,947 & 4.6 & $-1.49 / 0.036$ & $-1.89 / 0.027$ \\
\hline
\end{tabular}

a No.-The numbers correspond to the spot numbers indicated in Figure $1 \mathrm{~B} ;{ }^{\mathrm{b}}$ Average ratios of spot abundance of tachyplesin I-treated samples relative to the control, represent data from three separate experiments and student's $t$ test $p$ values are given as a measure of confidence for the ratio of each spot measured; ${ }^{\mathrm{c}} 0$ : control group; 10 : $10 \mu \mathrm{\mu g} / \mathrm{mL}$ dose group; $40: 40 \mu \mathrm{g} / \mathrm{mL}$ dose group; ${ }^{\mathrm{d}}$ Functional categories according to Gene ontology and panther biological process annotations; ${ }^{\mathrm{e}} \mathrm{ND}$, not detected or $p$ value $>0.5$. 


\subsection{Relative Quantification Using Dimethyl Labeling Based LC-MS/MS Analysis}

Peptide samples from the control, and $10 \mu \mathrm{g} / \mathrm{mL}$ and $40 \mu \mathrm{g} / \mathrm{mL}$ tachyplesin I-treated U251 gliomaspheres were labeled with dimethyl stable isotope tags. To obtain reliable quantification results, we conducted one forward and one reverse dimethyl labeling experiments. A total of 74,240 peptides from 4891 proteins were identified in the forward-labeling samples and 73,892 peptides from 4854 proteins in the reverse-labeling samples (Supplementary Materials Tables S1-S4). In both forward and reverse labeling experiment, the labeled peptides account for more than $99.8 \%$ of total identified peptides, indicating a good labeling efficiency. A total of 5737 proteins were reliably quantified in both the forward and reverse labeling experiments, of which 4008 proteins were overlapped (Figure 2B). The protein ratios of $\mathrm{L} / \mathrm{H}$ and $\mathrm{M} / \mathrm{H}$ in the forward labeling experiment and protein ratios of $\mathrm{M} / \mathrm{L}$ and $\mathrm{H} / \mathrm{L}$ in the reverse labeling experiment indicate the relative abundance of proteins in $10 \mu \mathrm{g} / \mathrm{mL}$ and $40 \mu \mathrm{g} / \mathrm{mL}$ tachyplesin I-treated groups compared to the control. The $\log _{2}$ transformed protein ratios between two different experimental groups all form a symmetric distribution curve with the peak around zero (the original ratio $=1$ ) (Figure 2A), and proteins that were increased or decreased in the forward-labeling experiment were also increased or decreased in the reverse-labeling experiment (Figure 2C), suggesting that there was no bias in the labeling and LC-MS experiments. Only those proteins with fold changes $>2$ and quantified in both forward and reverse labeling experiments were reported as differentially expressed proteins. Among 4088 proteins, the expression levels of 166 were significantly altered by tachyplesin I treatment. Among them, 55 were up-regulated (Table 2) while 111 proteins were down-regulated (Table 2). Figure 2D shows representative mass spectrometric results for the identification and quantification of the peptide DPDAQPGGELMLGGTDSK from cathepsin D, which clearly reveals the down-regulation of this protein in both sets of experiments.

A

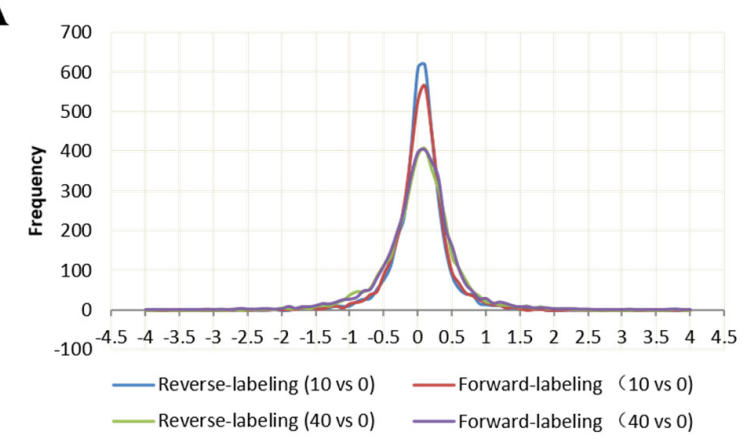

B

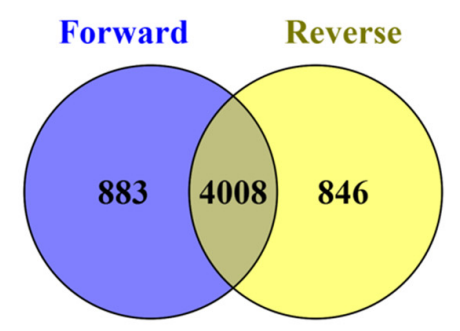

Total $=5737$

\section{C}
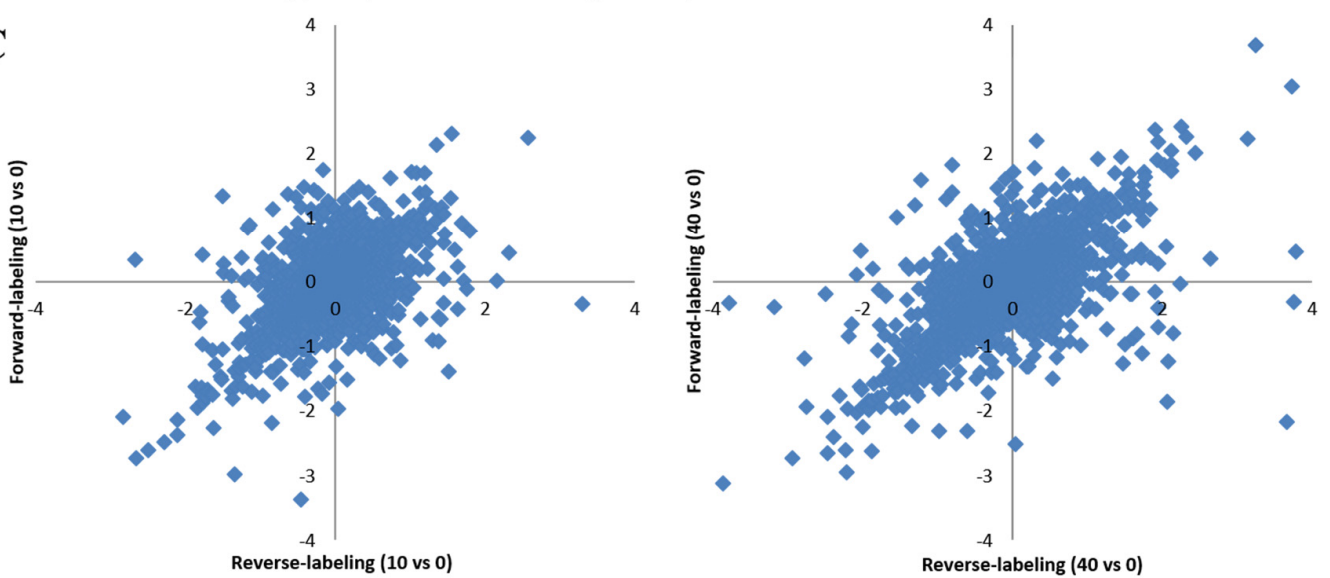

Figure 2. Cont. 

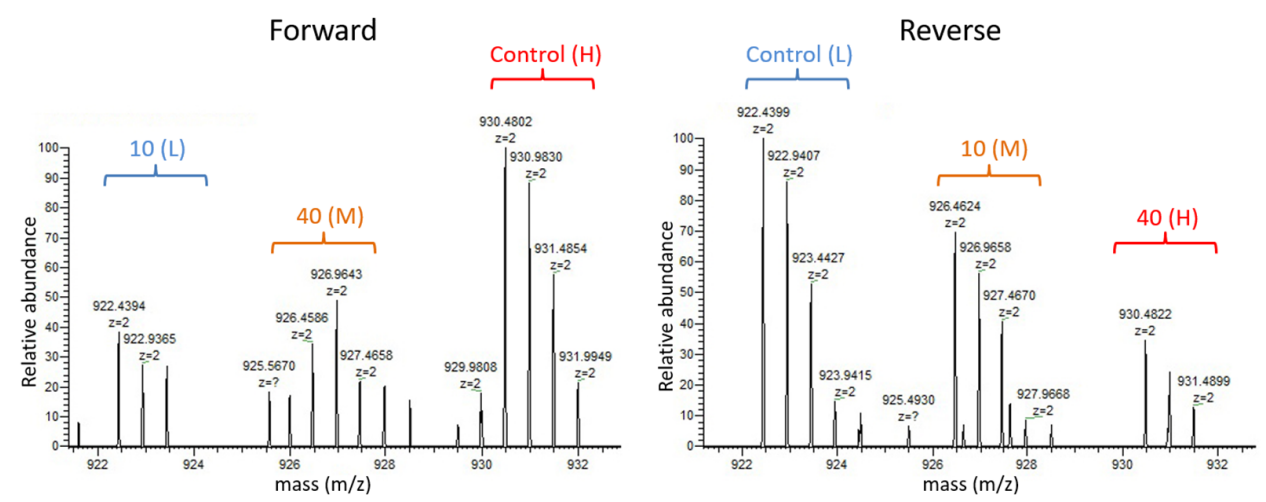

Figure 2. Dimethyl labeling based Liquid chromatography-mass spectrometry/mass spectrometry (LC-MS/MS) analysis of U251 gliomaspheres after treated with tachyplesin I. (A) Distribution of quantified protein $\log _{2}$ ratios; (B) A Venn diagram shows the number of proteins identified in either forward or reverse labeling experiment, as well as the overlap between them; (C) A scatter plot showing the forward ( $y$-axis) and reverse ( $x$-axis) dimethyl labeling $\log _{2}$ ratios for the 4008 proteins that were identified and quantified in both experiment, the left panel corresponds to $10 \mu \mathrm{g} / \mathrm{mL}$ group versus control, the right panel corresponds to $40 \mu \mathrm{g} / \mathrm{mL}$ group versus control. The values for each protein are shown as a blue diamond; (D) Representative mass spectrometric image revealing the tachyplesin I-induced down regulation of cathepsin D. Shown are the MS for the peptide DPDAQPGGELMLGGTDSK of cathepsin D from the forward (left panel) and reverse (right panel) dimethyl labeling samples.

\subsection{Cellular Functions of Differentially Expressed Proteins and Associated Pathways}

Systematic gene ontology (GO) analysis of 192 differentially expressed proteins identified from both 2D-DIGE and dimethyl labeling proteomic approaches was performed using PANTHER and DAVID tools. Molecular function analysis revealed that the majority of the differentially expressed proteins demonstrated catalytic $(42.93 \%)$, binding $(26.18 \%)$ and structural molecule activities $(10.99 \%)$ (Figure 3A). The biological processes altered by tachyplesin I treatment were most involved in metabolic processes $(30.13 \%)$, cellular processes $(19.88 \%)$, developmental processes $(8.43 \%)$, localization $(8.43 \%)$ and biological regulation (8.13\%) (Figure 3B). Kyoto Encyclopedia of Genes and Genomes (KEGG) pathways including lysosome pathway (15 proteins), glycosaminoglycan degradation pathway (6 proteins), antigen processing and presentation pathway (8 proteins), DNA replication pathway (5 proteins), type I diabetes mellitus pathway (4 proteins) and glycolysis/gluconeogenesis pathway (4 proteins) are the top pathways altered in response to tachyplesin I treatment (Table 3).

A

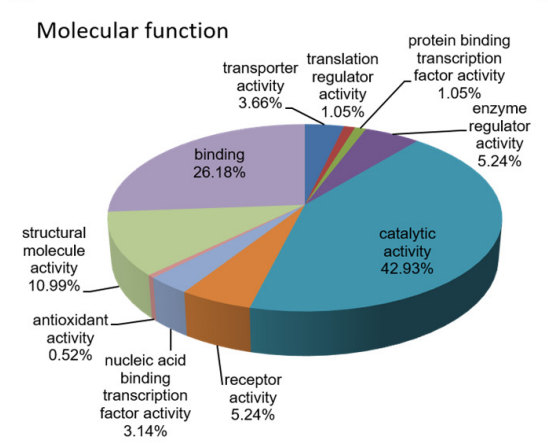

B

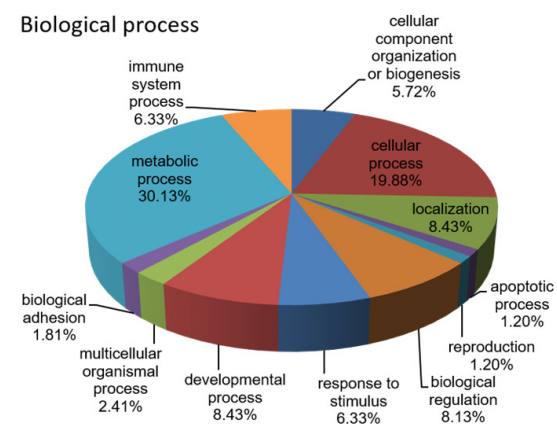

Figure 3. Gene ontology analysis of 192 differentially expressed proteins. The significant $(p \leq 0.001)$ molecular functions (A) and biological processes $(\mathbf{B})$ are presented in the pie chart. 
Table 2. List of proteins with altered expression in U251 gliomaspheres after treatment of tachyplesin I using dimethyl labeling quantitative proteomic analysis.

\begin{tabular}{|c|c|c|c|c|c|c|c|c|c|}
\hline \multicolumn{10}{|c|}{ The 55 Up-Regulated Proteins Expressed More Than 2 Folds ( $<1 \%$ FDR) } \\
\hline \multirow{2}{*}{ Gene Name } & \multirow{2}{*}{ Uniprot ID } & \multirow{2}{*}{ Protein Name } & \multirow{2}{*}{ Coverage $(\%)^{a}$} & \multirow{2}{*}{$\begin{array}{c}\text { Unique } \\
\text { Peptides a }\end{array}$} & \multicolumn{2}{|c|}{10 vs. 0 Ratio $^{b}$} & \multicolumn{2}{|c|}{40 vs. 0 Ratio $^{b}$} & \multirow{2}{*}{ Protein Class $^{c}$} \\
\hline & & & & & Forward & Reverse & Forward & Reverse & \\
\hline SPP1 & P10451 & Osteopontin & 33.12 & 5 & 4.961 & 2.943 & 12.876 & 9.484 & cytokine \\
\hline ITGB3 & P05106 & Integrin beta-3 & 5.20 & 3 & 4.754 & 5.953 & 13.279 & 28.714 & $\begin{array}{l}\text { receptor, extracellular } \\
\text { matrix glycoprotein }\end{array}$ \\
\hline EPS8 & Q12929 & $\begin{array}{l}\text { Epidermal growth factor receptor kinase } \\
\text { substrate } 8\end{array}$ & 4.01 & 3 & 4.403 & 2.549 & 2.220 & 2.305 & $\begin{array}{l}\text { transmembrane receptor } \\
\text { regulatory/adaptor protein }\end{array}$ \\
\hline MCM5 & B1AHB1 & DNA helicase & 5.50 & 3 & 3.304 & 2.022 & 3.801 & 2.194 & DNA helicase \\
\hline DKK1 & O94907 & Dickkopf-related protein 1 & 11.28 & 4 & 3.267 & 2.278 & 3.885 & 2.732 & $\begin{array}{l}\text { developmental protein, growth } \\
\text { factor activity }\end{array}$ \\
\hline MCM4 & P33991 & DNA replication licensing factor MCM4 & 7.76 & 4 & 3.248 & 2.119 & 5.189 & 3.723 & DNA binding protein \\
\hline NUSAP1 & Q9BXS6 & $\begin{array}{l}\text { Nucleolar and spindle-associated protein } \\
1\end{array}$ & 18.14 & 5 & 2.661 & 2.293 & 3.121 & 3.405 & microtubule-associated protein \\
\hline DHFR & P00374 & Dihydrofolate reductase & 24.06 & 4 & 2.616 & 2.168 & 2.398 & 2.472 & reductase \\
\hline TOP2A & P11388 & DNA topoisomerase 2-alpha & 12.93 & 12 & 2.490 & 2.916 & 3.259 & 2.582 & $\begin{array}{l}\text { DNA topoisomerase, } \\
\text { enzyme modulator }\end{array}$ \\
\hline MKI67 & A0A087WV66 & Antigen KI-67 & 12.66 & 24 & 2.396 & 1.870 & 2.688 & 2.047 & regulation of cell proliferation \\
\hline TFRC & P02786 & Transferrin receptor protein 1 & 35.79 & 23 & 2.323 & 2.398 & 2.906 & 2.879 & receptor \\
\hline AIM1 & Q9Y4K1 & Absent in melanoma 1 protein & 21.53 & 25 & 2.298 & 2.329 & 4.036 & 5.403 & carbohydrate binding protein \\
\hline ECE1 & P42892 & Endothelin-converting enzyme 1 & 15.19 & 8 & 2.260 & 2.671 & 3.557 & 4.070 & metalloprotease \\
\hline SYNJ2 & O15056 & Synaptojanin-2 & 8.76 & 11 & 2.239 & 2.501 & 5.349 & 4.740 & phosphatase \\
\hline KIF11 & P52732 & Kinesin-like protein KIF11 & 2.37 & 2 & 2.199 & 2.274 & 2.469 & 2.182 & $\begin{array}{l}\text { microtubule binding } \\
\text { motor protein }\end{array}$ \\
\hline DST & Q03001 & Dystonin & 23.49 & 21 & 2.113 & 1.596 & 2.614 & 2.051 & non-motor actin binding protein \\
\hline UPP1 & Q16831 & Uridine phosphorylase 1 & 46.45 & 11 & 2.078 & 2.712 & 2.209 & 3.577 & phosphorylase \\
\hline IGFBP5 & P24593 & $\begin{array}{l}\text { Insulin-like growth factor-binding } \\
\text { protein } 5\end{array}$ & 20.59 & 5 & 2.070 & 2.060 & 4.816 & 4.967 & cell communication \\
\hline RRM2 & P31350 & $\begin{array}{l}\text { Ribonucleoside-diphosphate reductase } \\
\text { subunit M2 }\end{array}$ & 34.45 & 11 & 2.030 & 1.981 & 2.286 & 2.423 & reductase \\
\hline $\mathrm{CD} 70$ & P32970 & CD70 antigen & 35.23 & 6 & 1.995 & 2.167 & 3.725 & 3.808 & cell communication \\
\hline MDK & E9PPJ5 & Midkine (Fragment) & 27.48 & 2 & 1.935 & 2.538 & 3.569 & 4.336 & cytokine \\
\hline HMGCS1 & Q01581 & $\begin{array}{l}\text { Hydroxymethylglutaryl-CoA } \\
\text { synthase, cytoplasmic }\end{array}$ & 42.88 & 17 & 1.929 & 1.939 & 3.322 & 4.339 & transferase, lyase \\
\hline
\end{tabular}


Table 2. Cont

\begin{tabular}{|c|c|c|c|c|c|c|c|c|c|}
\hline \multirow{2}{*}{ Gene Name } & \multirow{2}{*}{ Uniprot ID } & \multirow[b]{2}{*}{ Protein Name } & \multirow{2}{*}{ Coverage $(\%)^{a}$} & \multirow{2}{*}{$\begin{array}{c}\text { Unique } \\
\text { Peptides }^{\text {a }}\end{array}$} & \multicolumn{2}{|c|}{10 vs. 0 Ratio $^{b}$} & \multicolumn{2}{|c|}{40 vs. 0 Ratio $^{b}$} & \multirow{2}{*}{ Protein Class ${ }^{c}$} \\
\hline & & & & & Forward & Reverse & Forward & Reverse & \\
\hline DCLK1 & Q5VZY9 & Serine/threonine-protein kinase DCLK1 & 10.74 & 3 & 1.899 & 3.222 & 4.721 & 8.819 & $\begin{array}{l}\text { non-receptor serine/threonine } \\
\text { protein kinase }\end{array}$ \\
\hline MCM7 & P33993 & DNA replication licensing factor MCM7 & 13.21 & 7 & 1.879 & 1.963 & 2.451 & 2.470 & DNA helicase \\
\hline PODXL & O00592 & Podocalyxin & 2.33 & 1 & 1.870 & 2.234 & 2.474 & 2.856 & $\begin{array}{l}\text { regulation of adhesion and } \\
\text { cell morphology }\end{array}$ \\
\hline MCM2 & H0Y8E6 & $\begin{array}{l}\text { DNA replication licensing factor } \\
\text { MCM2 (Fragment) }\end{array}$ & 8.25 & 6 & 1.865 & 1.513 & 2.167 & 2.664 & DNA helicase \\
\hline LPL & P06858 & Lipoprotein lipase & 34.11 & 12 & 1.848 & 2.078 & 4.136 & 4.351 & storage protein \\
\hline VSNL1 & P62760 & Visinin-like protein 1 & 24.08 & 4 & 1.805 & 2.260 & 3.231 & 2.926 & cell communication \\
\hline MCM6 & Q14566 & DNA replication licensing factor MCM6 & 9.01 & 4 & 1.765 & 2.208 & 2.606 & 3.031 & DNA helicase \\
\hline GPC1 & P35052 & Glypican-1 & 33.69 & 14 & 1.745 & 1.665 & 2.861 & 3.347 & $\begin{array}{l}\text { cell division and } \\
\text { growth regulation }\end{array}$ \\
\hline TACC3 & Q9Y6A5 & $\begin{array}{l}\text { Transforming acidic coiled-coil-containing } \\
\text { protein } 3\end{array}$ & 3.22 & 2 & 1.735 & 2.068 & 2.563 & 2.322 & cytoskeleton \\
\hline TNC & $\mathrm{P} 24821$ & Tenascin & 40.16 & 5 & 1.730 & 1.803 & 2.327 & 2.112 & signaling molecule \\
\hline PLAT & P00750 & Tissue-type plasminogen activator & 24.73 & 12 & 1.729 & 3.475 & 8.267 & 13.172 & receptor, calmodulin \\
\hline GATM & P50440 & $\begin{array}{l}\text { Glycine amidinotransferase, } \\
\text { mitochondrial }\end{array}$ & 28.61 & 9 & 1.704 & 1.793 & 2.591 & 2.740 & catalyze creatine biosynthesis \\
\hline SERPINE1 & P05121 & Plasminogen activator inhibitor 1 & 21.14 & 7 & 1.695 & 1.448 & 4.539 & 3.853 & serine protease inhibitor \\
\hline LMCD1 & Q9NZU5 & LIM and cysteine-rich domains protein 1 & 38.63 & 10 & 1.681 & 1.686 & 2.388 & 2.243 & structural protein \\
\hline TYMS & P04818 & Thymidylate synthase & 19.17 & 4 & 1.675 & 2.752 & 2.151 & 3.228 & methyltransferase \\
\hline ITGA3 & P26006 & Integrin alpha-3 & 21.41 & 19 & 1.671 & 1.729 & 2.847 & 2.944 & receptor, integrin \\
\hline ANLN & Q9NQW6 & Actin-binding protein anillin & 3.91 & 3 & 1.666 & 2.235 & 2.308 & 3.143 & actin binding protein \\
\hline ANXA2 & P07355 & Annexin A2 & 81.42 & 34 & 1.617 & 1.610 & 2.023 & 2.100 & fatty acid metabolic process \\
\hline MACF1 & H3BPE1 & $\begin{array}{l}\text { Microtubule-actin cross-linking factor } 1 \text {, } \\
\text { isoforms } 1 / 2 / 3 / 5\end{array}$ & 29.64 & 153 & 1.610 & 1.601 & 2.018 & 2.000 & non-motor actin binding protein \\
\hline TPM4 & P67936 & Tropomyosin alpha-4 chain & 48.79 & 8 & 1.534 & 2.126 & 2.878 & 2.893 & actin binding motor protein \\
\hline ACTN4 & K7EJH8 & Alpha-actinin-4 (Fragment) & 68.68 & 1 & 1.526 & 2.411 & 2.251 & 3.153 & non-motor actin binding protein \\
\hline TRIM9 & Q9C026 & E3 ubiquitin-protein ligase TRIM9 & 4.23 & 3 & 1.508 & 1.143 & 2.077 & 2.109 & ubiquitin-protein ligase \\
\hline LDLR & P01130 & Low-density lipoprotein receptor & 6.63 & 5 & 1.498 & 1.202 & 2.266 & 2.096 & $\begin{array}{l}\text { receptor, extracellular } \\
\text { matrix glycoprotein }\end{array}$ \\
\hline SDCBP & $\mathrm{O} 00560$ & Syntenin-1 & 28.52 & 4 & 1.495 & 1.490 & 2.581 & 3.361 & $\begin{array}{l}\text { membrane trafficking } \\
\text { regulatory protein }\end{array}$ \\
\hline $\mathrm{TF}$ & P02787 & Serotransferrin & 45.13 & 27 & 1.422 & 1.526 & 2.224 & 2.216 & transfer/carrier protein \\
\hline
\end{tabular}


Table 2. Cont

\begin{tabular}{|c|c|c|c|c|c|c|c|c|c|}
\hline \multirow{2}{*}{ Gene Name } & \multirow{2}{*}{ Uniprot ID } & \multirow{2}{*}{ Protein Name } & \multirow{2}{*}{ Coverage (\%) ${ }^{a}$} & \multirow{2}{*}{$\begin{array}{c}\text { Unique } \\
\text { Peptides }^{\text {a }}\end{array}$} & \multicolumn{2}{|c|}{10 vs. 0 Ratio $^{b}$} & \multicolumn{2}{|c|}{40 vs. 0 Ratio $^{b}$} & \multirow{2}{*}{ Protein Class $^{c}$} \\
\hline & & & & & Forward & Reverse & Forward & Reverse & \\
\hline TENM2 & H7BYZ1 & Teneurin-2 & 13.86 & 24 & 1.422 & 1.735 & 2.046 & 2.501 & $\begin{array}{l}\text { receptor, membrane-bound } \\
\text { signaling molecule }\end{array}$ \\
\hline NES & P48681 & Nestin & 58.61 & 78 & 1.396 & 1.363 & 2.140 & 2.167 & structural protein \\
\hline THY1 & E9PIM6 & Thy-1 membrane glycoprotein (Fragment) & 25.66 & 3 & 1.360 & 1.468 & 2.432 & 2.131 & membrane glycoprotein \\
\hline NEFL & P07196 & Neurofilament light polypeptide & 47.88 & 28 & 1.213 & 1.182 & 2.121 & 2.010 & structural protein \\
\hline CLSTN1 & Q5SR54 & Calsyntenin-1 (Fragment) & 4.35 & 3 & 1.181 & 1.201 & 2.338 & 2.552 & $\begin{array}{l}\text { cell adhesion molecule, } \\
\text { calcium-binding protein }\end{array}$ \\
\hline $\mathrm{ECI} 2$ & A0A0C4DGA2 & $\begin{array}{l}\text { Enoyl-CoA delta } \\
\text { isomerase 2, mitochondrial }\end{array}$ & 40.38 & 11 & 1.148 & 1.262 & 2.239 & 2.894 & $\begin{array}{l}\text { transfer/carrier protein, } \\
\text { enzyme modulator }\end{array}$ \\
\hline PTPRE & P23469 & $\begin{array}{l}\text { Receptor-type tyrosine-protein } \\
\text { phosphatase epsilon }\end{array}$ & 11.29 & 5 & 0.939 & 2.069 & 3.282 & 3.385 & receptor, protein phosphatase \\
\hline LRRC16A & Q5VZK9 & $\begin{array}{l}\text { Leucine-rich repeat-containing } \\
\text { protein } 16 \mathrm{~A}\end{array}$ & 1.90 & 2 & ND & 1.408 & 2.281 & 3.321 & transcription cofactor \\
\hline \multicolumn{10}{|c|}{ The 111 Down-Regulated Proteins Expressed Less Than 0.5 Folds ( $<1 \%$ FDR) } \\
\hline OASL & Q15646 & $2^{\prime}-5^{\prime}$-oligoadenylate synthase-like protein & 12.26 & 4 & 0.127 & 0.393 & 0.215 & ND & $\begin{array}{l}\text { nucleotidyltransferase, } \\
\text { defense/immunity protein }\end{array}$ \\
\hline OAS2 & P29728 & $2^{\prime}-5^{\prime}$-oligoadenylate synthase 2 & 9.74 & 9 & 0.151 & 0.158 & 0.115 & 0.068 & $\begin{array}{l}\text { nucleotidyltransferase, } \\
\text { defense/immunity protein }\end{array}$ \\
\hline MX1 & P20591 & $\begin{array}{l}\text { Interferon-induced GTP-binding } \\
\text { protein } \mathrm{Mx} 1\end{array}$ & 56.50 & 28 & 0.164 & 0.177 & 0.150 & 0.130 & $\begin{array}{l}\text { microtubule family } \\
\text { cytoskeletal protein }\end{array}$ \\
\hline IFI44L & Q53G44 & Interferon-induced protein 44 -like & 39.60 & 13 & 0.179 & 0.206 & 0.189 & 0.191 & immune response \\
\hline IFI44 & Q8TCB0 & Interferon-induced protein 44 & 33.56 & 13 & 0.193 & 0.231 & 0.158 & 0.181 & immune response \\
\hline CASP1 & G3V169 & Caspase & 19.35 & 4 & 0.209 & 0.325 & 0.235 & 0.180 & regulation of apoptotic proces \\
\hline BTN3A2 & E9PRR1 & $\begin{array}{l}\text { Butyrophilin subfamily } 3 \text { member } \\
\text { A2 (Fragment) }\end{array}$ & 27.55 & 2 & 0.220 & 0.555 & 0.261 & 0.360 & ubiquitin-protein ligase \\
\hline INS & C9JNR5 & Insulin (Fragment) & 7.61 & 1 & 0.228 & 0.231 & 0.634 & 0.769 & growth factor \\
\hline MX2 & P20592 & $\begin{array}{l}\text { Interferon-induced GTP-binding } \\
\text { protein } \mathrm{Mx2}\end{array}$ & 16.05 & 5 & 0.235 & 0.140 & 0.129 & 0.215 & $\begin{array}{l}\text { microtubule family } \\
\text { cytoskeletal protein }\end{array}$ \\
\hline PARP10 & E9PPE7 & Poly [ADP-ribose] polymerase 10 & 4.71 & 2 & 0.260 & 0.280 & 0.201 & 0.508 & nucleic acid binding \\
\hline ISG15 & A0A096LNZ9 & Ubiquitin-like protein ISG15 (Fragment) & 50.35 & 6 & 0.273 & 0.293 & 0.253 & 0.264 & ribosomal protein \\
\hline TAP1 & Q03518 & Antigen peptide transporter 1 & 29.08 & 15 & 0.287 & 0.385 & 0.288 & 0.288 & $\begin{array}{l}\text { ATP-binding cassette } \\
(\mathrm{ABC}) \text { transporter }\end{array}$ \\
\hline IFIT3 & O14879 & $\begin{array}{l}\text { Interferon-induced protein with } \\
\text { tetratricopeptide repeats } 3\end{array}$ & 48.57 & 18 & 0.288 & 0.301 & 0.261 & 0.258 & RNA binding \\
\hline
\end{tabular}


Table 2. Cont

\begin{tabular}{|c|c|c|c|c|c|c|c|c|c|}
\hline \multirow[b]{2}{*}{ Gene Name } & \multirow[b]{2}{*}{ Uniprot ID } & \multirow[b]{2}{*}{ Protein Name } & \multirow{2}{*}{ Coverage $(\%)^{a}$} & \multirow{2}{*}{$\begin{array}{c}\text { Unique } \\
\text { Peptides }^{\text {a }}\end{array}$} & \multicolumn{2}{|c|}{10 vs. 0 Ratio $^{b}$} & \multicolumn{2}{|c|}{40 vs. 0 Ratio $^{b}$} & \multirow{2}{*}{ Protein Class $^{c}$} \\
\hline & & & & & Forward & Reverse & Forward & Reverse & \\
\hline IFIT2 & P09913 & $\begin{array}{l}\text { Interferon-induced protein with } \\
\text { tetratricopeptide repeats } 2\end{array}$ & 30.08 & 11 & 0.294 & 0.291 & 0.212 & 0.250 & RNA binding \\
\hline IFIT1 & P09914 & $\begin{array}{l}\text { Interferon-induced protein with } \\
\text { tetratricopeptide repeats } 1\end{array}$ & 45.82 & 16 & 0.300 & 0.321 & 0.296 & 0.301 & RNA binding \\
\hline KRT10 & P13645 & Keratin, type I cytoskeletal 10 & 30.14 & 13 & 0.301 & 0.314 & 0.483 & 0.541 & structural protein \\
\hline DDX58 & O95786 & $\begin{array}{l}\text { Probable ATP-dependent RNA } \\
\text { helicase DDX58 }\end{array}$ & 41.73 & 37 & 0.307 & 0.307 & 0.278 & 0.265 & helicase, hydrolase \\
\hline BLOC1S1 & G8JLQ3 & $\begin{array}{l}\text { Biogenesis of lysosome-related organelles } \\
\text { complex } 1 \text { subunit } 1\end{array}$ & 50.67 & 3 & 0.308 & 0.461 & 0.296 & 0.417 & transcription factor \\
\hline TRIM21 & P19474 & E3 ubiquitin-protein ligase TRIM21 & 7.79 & 3 & 0.310 & 0.382 & 0.259 & 0.340 & ubiquitin-protein ligase \\
\hline OAS3 & Q9Y6K5 & $2^{\prime}-5^{\prime}$-oligoadenylate synthase 3 & 30.08 & 29 & 0.316 & 0.306 & 0.246 & 0.237 & $\begin{array}{l}\text { nucleotidyltransferase, } \\
\text { defense/immunity protein }\end{array}$ \\
\hline SLC4A4 & Q9Y6R1 & $\begin{array}{l}\text { Electrogenic sodium bicarbonate } \\
\text { cotransporter } 1\end{array}$ & 9.64 & 8 & 0.323 & 0.290 & 0.164 & 0.214 & transporter \\
\hline ТАРВР & O15533 & Tapasin & 25.00 & 7 & 0.324 & 0.397 & 0.318 & 0.333 & $\begin{array}{l}\text { immunoglobulin receptor } \\
\text { superfamily }\end{array}$ \\
\hline KRT1 & P04264 & Keratin, type II cytoskeletal 1 & 36.49 & 18 & 0.325 & 0.273 & 0.550 & 0.447 & structural protein \\
\hline DTX3L & Q8TDB6 & E3 ubiquitin-protein ligase DTX3L & 25.81 & 12 & 0.326 & 0.426 & 0.375 & 0.377 & ubiquitin-protein ligase \\
\hline TAP2 & Q03519 & Antigen peptide transporter 2 & 22.16 & 10 & 0.350 & 0.350 & 0.280 & 0.270 & $\begin{array}{l}\text { ATP-binding cassette } \\
\text { (ABC) transporter }\end{array}$ \\
\hline GBP1 & P32455 & $\begin{array}{l}\text { Interferon-induced guanylate-binding } \\
\text { protein } 1\end{array}$ & 28.38 & 13 & 0.362 & 0.346 & 0.296 & 0.202 & heterotrimeric G-protein \\
\hline KRT9 & P35527 & Keratin, type I cytoskeletal 9 & 35.47 & 15 & 0.363 & 0.409 & 0.632 & 0.759 & structural protein \\
\hline AGTRAP & Q6RW13 & $\begin{array}{l}\text { Type- } 1 \text { angiotensin II } \\
\text { receptor-associated protein }\end{array}$ & 13.84 & 1 & 0.383 & 0.479 & 0.557 & 0.604 & response to hypoxia \\
\hline PARP9 & Q8IXQ6 & Poly [ADP-ribose] polymerase 9 & 16.28 & 12 & 0.387 & 0.392 & 0.395 & 0.359 & nucleic acid binding \\
\hline HLA-B & P30466 & $\begin{array}{l}\text { HLA class I histocompatibility antigen, } \\
\text { B-18 alpha chain }\end{array}$ & 57.73 & 1 & 0.396 & 0.414 & 0.307 & 0.344 & $\begin{array}{l}\text { immunoglobulin } \\
\text { receptor superfamily }\end{array}$ \\
\hline IRF9 & Q00978 & Interferon regulatory factor 9 & 7.38 & 3 & 0.405 & 0.588 & 0.318 & 0.377 & immune response \\
\hline C19orf66 & Q9NUL5 & UPF0515 protein C19orf66 & 16.15 & 3 & 0.405 & 0.480 & 0.214 & 0.395 & no function identified yet \\
\hline NT5E & P21589 & $5^{\prime}$-nucleotidase & 48.08 & 25 & 0.408 & 0.428 & 0.353 & 0.361 & nucleotide phosphatase \\
\hline STAT1 & P42224 & $\begin{array}{l}\text { Signal transducer and activator of } \\
\text { transcription 1-alpha/beta }\end{array}$ & 53.33 & 36 & 0.408 & 0.422 & 0.369 & 0.381 & $\begin{array}{l}\text { transcription factor, nucleic } \\
\text { acid binding }\end{array}$ \\
\hline KRT2 & P35908 & Keratin, type II cytoskeletal 2 epidermal & 7.82 & 3 & 0.411 & 0.329 & 0.428 & 0.471 & structural protein \\
\hline
\end{tabular}


Table 2. Cont

\begin{tabular}{|c|c|c|c|c|c|c|c|c|c|}
\hline \multirow{2}{*}{ Gene Name } & \multirow{2}{*}{ Uniprot ID } & \multirow{2}{*}{ Protein Name } & \multirow{2}{*}{ Coverage $(\%)^{a}$} & \multirow{2}{*}{$\begin{array}{l}\text { Unique } \\
\text { Peptides }^{a}\end{array}$} & \multicolumn{2}{|c|}{10 vs. 0 Ratio $^{b}$} & \multicolumn{2}{|c|}{40 vs. 0 Ratio $^{b}$} & \multirow{2}{*}{ Protein Class $^{c}$} \\
\hline & & & & & Forward & Reverse & Forward & Reverse & \\
\hline SP100 & P23497 & Nuclear autoantigen Sp-100 & 9.56 & 6 & 0.412 & 0.438 & 0.352 & 0.363 & $\begin{array}{l}\text { HMG box transcription factor, } \\
\text { signaling molecule }\end{array}$ \\
\hline B2M & P61769 & Beta-2-microglobulin & 37.82 & 4 & 0.419 & 0.413 & 0.369 & 0.332 & $\begin{array}{l}\text { major histocompatibility } \\
\text { complex antigen }\end{array}$ \\
\hline ALB & A0A0C4DGB6 & Serum albumin & 16.89 & 9 & 0.427 & 0.455 & 0.668 & 0.654 & transfer/carrier protein \\
\hline BANF1 & O75531 & Barrier-to-autointegration factor & 34.83 & 2 & 0.429 & 0.467 & 0.308 & 0.408 & DNA binding, DNA integration \\
\hline IFIT5 & Q13325 & $\begin{array}{l}\text { Interferon-induced protein with } \\
\text { tetratricopeptide repeats } 5\end{array}$ & 19.71 & 7 & 0.438 & 0.497 & 0.477 & 0.435 & RNA-binding \\
\hline ERAP2 & Q6P179 & Endoplasmic reticulum aminopeptidase 2 & 6.25 & 5 & 0.461 & 0.527 & 0.371 & 0.457 & metalloprotease \\
\hline HLA-A & P01892 & $\begin{array}{l}\text { HLA class I histocompatibility antigen, } \\
\text { A-2 alpha chain }\end{array}$ & 64.38 & 15 & 0.465 & 0.509 & 0.415 & 0.447 & $\begin{array}{l}\text { immunoglobulin receptor } \\
\text { superfamily }\end{array}$ \\
\hline NDRG1 & Q92597 & Protein NDRG1 & 27.41 & 6 & 0.468 & 0.541 & 0.260 & 0.246 & stress-responsive protein \\
\hline STAT2 & P52630 & $\begin{array}{l}\text { Signal transducer and activator of } \\
\text { transcription } 2\end{array}$ & 10.93 & 5 & 0.478 & 0.617 & 0.347 & 0.442 & $\begin{array}{l}\text { transcription factor, nucleic acid } \\
\text { binding }\end{array}$ \\
\hline HLA-E & P13747 & $\begin{array}{l}\text { HLA class I histocompatibility antigen, } \\
\text { alpha chain E }\end{array}$ & 24.02 & 2 & 0.479 & 0.319 & 0.472 & 0.433 & $\begin{array}{l}\text { immunoglobulin receptor } \\
\text { superfamily }\end{array}$ \\
\hline ATP6V0C & P27449 & $\begin{array}{l}\text { V-type proton ATPase } 16 \mathrm{kDa} \text { proteolipid } \\
\text { subunit }\end{array}$ & 11.61 & 1 & 0.484 & 0.353 & 0.906 & 0.805 & hydrolase, ATP synthase \\
\hline UCHL3 & P15374 & $\begin{array}{l}\text { Ubiquitin carboxyl-terminal hydrolase } \\
\text { isozyme L3 }\end{array}$ & 15.65 & 2 & 0.492 & 0.459 & 0.558 & 0.220 & cysteine protease \\
\hline EPN2 & F6PQP6 & Epsin-2 (Fragment) & 19.56 & 7 & 0.496 & 0.576 & 0.262 & 0.295 & endocytosis \\
\hline DBI & P07108 & Acyl-CoA-binding protein & 65.52 & 6 & 0.501 & 0.502 & 0.263 & 0.148 & transfer/carrier protein \\
\hline SP110 & G5E9C0 & $\begin{array}{l}\text { SP110 nuclear body protein, isoform } \\
\text { CRA_b }\end{array}$ & 5.48 & 2 & 0.506 & 0.473 & 0.464 & 0.439 & $\begin{array}{l}\text { HMG box transcription factor, } \\
\text { signaling molecule }\end{array}$ \\
\hline TCEAL3 & Q969E4 & $\begin{array}{l}\text { Transcription elongation factor A } \\
\text { protein-like } 3\end{array}$ & 16.50 & 2 & 0.507 & 0.478 & 0.354 & 0.307 & transcription factor \\
\hline LGALS3BP & Q08380 & Galectin-3-binding protein & 39.83 & 19 & 0.507 & 0.533 & 0.427 & 0.457 & receptor, serine protease \\
\hline UBE2L6 & O14933 & $\begin{array}{l}\text { Ubiquitin/ISG15-conjugating enzyme E2 } \\
\text { L6 }\end{array}$ & 59.48 & 5 & 0.517 & 0.407 & 0.382 & 0.317 & ligase \\
\hline SMYD2 & Q9NRG4 & N-lysine methyltransferase SMYD2 & 7.39 & 3 & 0.519 & 0.669 & 0.327 & 0.243 & transcription cofactor \\
\hline TREX1 & Q9NSU2 & Three-prime repair exonuclease 1 & 7.86 & 2 & 0.526 & 0.463 & 0.482 & 0.389 & catalytic activityi \\
\hline AK4 & P27144 & Adenylate kinase 4 , mitochondrial & 49.33 & 8 & 0.529 & 0.500 & 0.381 & 0.422 & nucleotide kinase \\
\hline FAM96B & J3KS95 & $\begin{array}{l}\text { Mitotic spindle-associated MMXD } \\
\text { complex subunit MIP18 (Fragment) }\end{array}$ & 23.58 & 2 & 0.539 & 0.421 & 0.452 & 0.473 & iron-sulfur cluster assembly \\
\hline
\end{tabular}


Table 2. Cont

\begin{tabular}{|c|c|c|c|c|c|c|c|c|c|}
\hline \multirow{2}{*}{ Gene Name } & \multirow{2}{*}{ Uniprot ID } & \multirow{2}{*}{ Protein Name } & \multirow{2}{*}{ Coverage $(\%)^{a}$} & \multirow{2}{*}{$\begin{array}{c}\text { Unique } \\
\text { Peptides }^{\text {a }}\end{array}$} & \multicolumn{2}{|c|}{10 vs. 0 Ratio $^{b}$} & \multicolumn{2}{|c|}{40 vs. 0 Ratio $^{b}$} & \multirow{2}{*}{ Protein Class ${ }^{c}$} \\
\hline & & & & & Forward & Reverse & Forward & Reverse & \\
\hline DPP7 & Q9UHL4 & Dipeptidyl peptidase 2 & 35.37 & 12 & 0.541 & 0.581 & 0.365 & 0.431 & serine protease \\
\hline PML & P29590 & Protein PML & 33.79 & 22 & 0.545 & 0.558 & 0.424 & 0.392 & activator \\
\hline AGA & P20933 & $\mathrm{N}(4)$-(beta- $N$-acetylglucosaminyl)-L-asparaginase & ase 24.86 & 5 & 0.551 & 0.635 & 0.415 & 0.490 & protease \\
\hline EPHA2 & P29317 & Ephrin type-A receptor 2 & 19.67 & 15 & 0.555 & 0.523 & 0.386 & 0.395 & nervous system development \\
\hline SERPINI1 & Q99574 & Neuroserpin & 8.78 & 3 & 0.564 & 0.757 & 0.257 & 0.217 & serine protease inhibitor \\
\hline PAPSS2 & O95340 & $\begin{array}{l}\text { Bifunctional 3'-phosphoadenosine } \\
5^{\prime} \text {-phosphosulfate synthase } 2\end{array}$ & 37.30 & 18 & 0.567 & 0.544 & 0.336 & 0.276 & nucleotidyltransferase \\
\hline IDUA & P35475 & Alpha-L-iduronidase & 31.85 & 16 & 0.572 & 0.605 & 0.416 & 0.479 & glycosidase \\
\hline GLA & P06280 & Alpha-galactosidase A & 25.64 & 8 & 0.574 & 0.625 & 0.464 & 0.435 & glycosidase, hydrolase \\
\hline SGSH & P51688 & $\mathrm{N}$-sulphoglucosamine sulphohydrolase & 29.68 & 11 & 0.578 & 0.515 & 0.353 & 0.410 & hydrolase \\
\hline GAA & P10253 & Lysosomal alpha-glucosidase & 24.37 & 19 & 0.584 & 0.657 & 0.426 & 0.461 & glucosidase \\
\hline CHSY3 & Q70JA7 & Chondroitin sulfate synthase 3 & 6.92 & 6 & 0.587 & 0.483 & 0.361 & 0.320 & glycosyltransferase \\
\hline ACP5 & K7EIP0 & $\begin{array}{l}\text { Tartrate-resistant acid phosphatase } \\
\text { type } 5 \text { (Fragment) }\end{array}$ & 36.54 & 1 & 0.587 & 0.544 & 0.313 & 0.246 & $\begin{array}{l}\text { glycosylated monomeric } \\
\text { metalloprotein enzyme }\end{array}$ \\
\hline PSMB8 & $\mathrm{P} 28062$ & Proteasome subunit beta type- 8 & 39.13 & 8 & 0.590 & 0.552 & 0.455 & 0.493 & endopeptidase activity \\
\hline SPTBN2 & O15020 & Spectrin beta chain, non-erythrocytic 2 & 4.35 & 2 & 0.593 & 0.738 & 0.389 & 0.358 & non-motor actin binding protein \\
\hline PGM2L1 & Q6PCE3 & Glucose 1,6-bisphosphate synthase & 48.07 & 30 & 0.598 & 0.627 & 0.492 & 0.448 & glycosyltransferase, mutase \\
\hline SAMD9L & Q8IVG5 & $\begin{array}{l}\text { Sterile alpha motif domain-containing } \\
\text { protein 9-like }\end{array}$ & 4.67 & 6 & 0.611 & 0.547 & 0.489 & 0.416 & $\begin{array}{l}\text { regulation of protein } \\
\text { catabolic process }\end{array}$ \\
\hline CSTB & P04080 & Cystatin-B & 45.92 & 3 & 0.615 & 0.680 & 0.328 & 0.380 & cysteine protease inhibitor \\
\hline LGMN & Q99538 & Legumain & 10.39 & 4 & 0.618 & 0.636 & 0.483 & 0.499 & cysteine protease \\
\hline $\mathrm{CPQ}$ & Q9Y646 & Carboxypeptidase Q & 20.55 & 7 & 0.620 & 0.631 & 0.406 & 0.452 & carboxypeptidase activity \\
\hline CTSA & P10619 & Lysosomal protective protein & 18.75 & 9 & 0.626 & 0.667 & 0.418 & 0.422 & serine protease \\
\hline NAGA & P17050 & Alpha- $N$-acetylgalactosaminidase & 11.92 & 3 & 0.626 & 0.648 & 0.480 & 0.287 & deacetylase \\
\hline ENO2 & P09104 & Gamma-enolase & 60.83 & 11 & 0.631 & 0.676 & 0.436 & 0.494 & lyase \\
\hline GALNS & P34059 & $\mathrm{N}$-acetylgalactosamine-6-sulfatase & 8.62 & 5 & 0.633 & 0.687 & 0.436 & 0.377 & hydrolase \\
\hline KCTD12 & Q96CX2 & $\begin{array}{l}\text { BTB/POZ domain-containing } \\
\text { protein KCTD12 }\end{array}$ & 33.23 & 11 & 0.634 & 0.624 & 0.446 & 0.480 & enzyme modulator \\
\hline GOLIM4 & O00461 & Golgi integral membrane protein 4 & 18.25 & 11 & 0.638 & 0.671 & 0.391 & 0.416 & transport \\
\hline NMRK1 & B3KN26 & Nicotinamide riboside kinase 1 & 12.26 & 1 & 0.641 & 0.527 & 0.422 & 0.402 & kinase \\
\hline RNASET2 & D6REQ6 & Ribonuclease T2 & 19.27 & 4 & 0.643 & 0.545 & 0.398 & 0.400 & endoribonuclease activity \\
\hline
\end{tabular}


Table 2. Cont

\begin{tabular}{|c|c|c|c|c|c|c|c|c|c|}
\hline \multirow{2}{*}{ Gene Name } & \multirow{2}{*}{ Uniprot ID } & \multirow{2}{*}{ Protein Name } & \multirow{2}{*}{ Coverage $(\%)^{a}$} & \multirow{2}{*}{$\begin{array}{c}\text { Unique } \\
\text { Peptides }{ }^{\text {a }}\end{array}$} & \multicolumn{2}{|c|}{10 vs. 0 Ratio $^{b}$} & \multicolumn{2}{|c|}{40 vs. 0 Ratio $^{b}$} & \multirow{2}{*}{ Protein Class ${ }^{c}$} \\
\hline & & & & & Forward & Reverse & Forward & Reverse & \\
\hline TUBB2B & Q9BVA1 & Tubulin beta-2B chain & 74.16 & 1 & 0.643 & 0.545 & 0.424 & 0.318 & tubulin \\
\hline MTAP & Q13126 & S-methyl-5'-thioadenosine phosphorylase & 71.38 & 15 & 0.645 & 0.683 & 0.484 & 0.492 & phosphorylase \\
\hline NAGLU & P54802 & Alpha- $N$-acetylglucosaminidase & 26.11 & 13 & 0.646 & 0.706 & 0.466 & 0.478 & glycosidase, hydrolase \\
\hline TXNIP & Q9H3M7 & Thioredoxin-interacting protein & 16.11 & 6 & 0.650 & 0.441 & 0.479 & 0.351 & $\begin{array}{l}\text { transcription regulation, } \\
\text { oxidative stress mediator }\end{array}$ \\
\hline BCAR3 & O75815 & $\begin{array}{l}\text { Breast cancer anti-estrogen resistance } \\
\text { protein } 3\end{array}$ & 7.88 & 4 & 0.652 & 0.285 & 0.162 & 0.272 & $\begin{array}{l}\text { guanine-nucleotide } \\
\text { releasing factor }\end{array}$ \\
\hline GUSB & P08236 & Beta-glucuronidase & 26.42 & 16 & 0.678 & 0.649 & 0.495 & 0.452 & galactosidase \\
\hline PGK1 & P00558 & Phosphoglycerate kinase 1 & 84.41 & 31 & 0.686 & 0.647 & 0.461 & 0.437 & carbohydrate kinase \\
\hline H6PD & O95479 & $\begin{array}{l}\text { GDH/6PGL endoplasmic } \\
\text { bifunctional protein }\end{array}$ & 35.65 & 23 & 0.708 & 0.729 & 0.477 & 0.483 & dehydrogenase \\
\hline CSRP1 & P21291 & Cysteine and glycine-rich protein 1 & 64.25 & 9 & 0.711 & 0.670 & 0.426 & 0.427 & actin family cytoskeletal proteir \\
\hline CPVL & Q9H3G5 & Probable serine carboxypeptidase CPVL & 21.22 & 9 & 0.711 & 0.640 & 0.480 & 0.453 & serine protease \\
\hline NNMT & P40261 & Nicotinamide $N$-methyltransferase & 56.06 & 10 & 0.713 & 0.667 & 0.335 & 0.333 & methyltransferase \\
\hline EXTL3 & O43909 & Exostosin-like 3 & 15.34 & 13 & 0.737 & 0.807 & 0.433 & 0.472 & glycosyltransferase \\
\hline VLDLR & P98155 & Very low-density lipoprotein receptor & 8.48 & 6 & 0.738 & 0.699 & 0.460 & 0.478 & $\begin{array}{l}\text { receptor, extracellular } \\
\text { matrix glycoprotein }\end{array}$ \\
\hline MMP14 & P50281 & Matrix metalloproteinase-14 & 19.76 & 11 & 0.748 & 0.800 & 0.344 & 0.361 & $\begin{array}{l}\text { hydrolase, } \\
\text { metalloprotease, protease }\end{array}$ \\
\hline OSTF1 & Q92882 & Osteoclast-stimulating factor 1 & 53.74 & 9 & 0.750 & 0.649 & 0.459 & 0.463 & signal transduction \\
\hline AKAP2 & Q9Y2D5 & A-kinase anchor protein 2 & 15.83 & 7 & 0.751 & 0.773 & 0.410 & 0.468 & $\begin{array}{l}\text { regulation of cell cycle, } \\
\text { apoptosis process }\end{array}$ \\
\hline SIAE & Q9HAT2 & Sialate $O$-acetylesterase & 12.05 & 5 & 0.769 & 0.725 & 0.346 & 0.294 & esterase \\
\hline MRC2 & Q9UBG0 & C-type mannose receptor 2 & 11.36 & 13 & 0.778 & 0.867 & 0.379 & 0.454 & receptor \\
\hline IDS & P22304 & Iduronate 2-sulfatase & 23.82 & 9 & 0.784 & 0.812 & 0.425 & 0.465 & hydrolase \\
\hline CNTNAP1 & P78357 & Contactin-associated protein 1 & 2.02 & 2 & 0.792 & 0.638 & 0.403 & 0.436 & $\begin{array}{l}\text { transporter, membrane-bound } \\
\text { signaling molecule, receptor }\end{array}$ \\
\hline AKR1C3 & S4R3Z2 & Aldo-keto reductase family 1 member $\mathrm{C} 3$ & 6.67 & 1 & 0.828 & 0.645 & 0.305 & 0.337 & reductase \\
\hline
\end{tabular}


Table 2. Cont

\begin{tabular}{|c|c|c|c|c|c|c|c|c|c|}
\hline \multirow{2}{*}{ Gene Name } & \multirow{2}{*}{ Uniprot ID } & \multirow{2}{*}{ Protein Name } & \multirow{2}{*}{ Coverage $(\%)^{a}$} & \multirow{2}{*}{$\begin{array}{c}\text { Unique } \\
\text { Peptides }{ }^{\text {a }}\end{array}$} & \multicolumn{2}{|c|}{10 vs. 0 Ratio $^{b}$} & \multicolumn{2}{|c|}{40 vs. 0 Ratio $^{b}$} & \multirow{2}{*}{ Protein Class $^{c}$} \\
\hline & & & & & Forward & Reverse & Forward & Reverse & \\
\hline AMDHD2 & Q9Y303 & $\begin{array}{l}\text { Putative } \\
N \text {-acetylglucosamine-6-phosphate } \\
\text { deacetylase }\end{array}$ & 8.07 & 2 & 0.840 & 0.548 & 0.465 & 0.473 & deacetylase \\
\hline MANBA & O00462 & Beta-mannosidase & 6.60 & 3 & 0.901 & 0.799 & 0.356 & 0.482 & galactosidase \\
\hline SH3BP5L & Q7L8J4 & SH3 domain-binding protein 5-like & 5.09 & 2 & 0.912 & 0.931 & 0.354 & 0.411 & protein kinase inhibitor \\
\hline LRP1 & Q07954 & $\begin{array}{l}\text { Prolow-density lipoprotein } \\
\text { receptor-related protein } 1\end{array}$ & 0.62 & 3 & 1.068 & 0.617 & 0.381 & 0.478 & $\begin{array}{l}\text { receptor, extracellular } \\
\text { matrix glycoprotein }\end{array}$ \\
\hline ATF7IP & F5GYR7 & $\begin{array}{l}\text { Activating transcription factor } \\
\text { 7-interacting protein } 1 \text { (Fragment) }\end{array}$ & 9.38 & 1 & ND & 0.447 & 0.441 & 0.146 & transcription regulation \\
\hline VPS29 & Q9UBQ0 & $\begin{array}{l}\text { Vacuolar protein sorting-associated } \\
\text { protein } 29\end{array}$ & 56.04 & 1 & ND & 0.922 & 0.473 & 0.474 & vesicle coat protein \\
\hline
\end{tabular}

${ }^{a}$ The values of coverage and unique peptides are based on forward labeling result; ${ }^{b}$ Ratios: Spot abundance of tachyplesin I-treated samples relative to the control; 0 : control group 10: $10 \mu \mathrm{g} / \mathrm{mL}$ dose group; $40: 40 \mu \mathrm{g} / \mathrm{mL}$ dose group; forward: forward labeling group; reverse: reverse labeling group; ${ }^{\mathrm{c}}$ Functional categories according to Gene ontology and panther biological process annotations. 
Table 3. List of altered KEGG pathways with tachyplesin I treatment and their $p$-values identified by bioinformatic analysis using DAVID $(p<0.1)$.

\begin{tabular}{cll}
\hline Pathways & $p$ Value & $\begin{array}{l}\text { Differentially Expressed Proteins Involved in } \\
\text { This Pathway }\end{array}$ \\
\hline $\begin{array}{c}\text { Lysosome } \\
\begin{array}{c}\text { Glycosaminoglycan } \\
\text { degradation }\end{array}\end{array}$ & $1.11 \times 10^{-8}$ & $\begin{array}{l}\text { SGSH, AGA, NAGLU, GUSB, LGMN, ACP5, } \\
\text { CTSA, MANBA, ATP6V0C, GLA, IDS, GALNS, } \\
\text { NAGA, GAA, IDUA }\end{array}$ \\
\hline $\begin{array}{c}\text { Antigen processing and } \\
\text { presentation }\end{array}$ & $2.53 \times 10^{-5}$ & SGSH, NAGLU, IDS, GUSB, GALNS, IDUA \\
\hline DNA replication & $5.99 \times 10^{-4}$ & $\begin{array}{l}\text { TAP2, LGMN, TAP1, HLA-A, HLA-B, HLA-E, } \\
\text { TAPBP, B2M }\end{array}$ \\
\hline Type I diabetes mellitus & $3.51 \times 10^{-3}$ & MCM7, MCM2, MCM4, MCM5, MCM6 \\
\hline Glycolysis/Gluconeogenesis & $3.75 \times 10^{-2}$ & INS, HLA-A, HLA-B, HLA-E \\
\hline
\end{tabular}

\section{4. tachyplesin I Influences Metabolic Process and Alters the Expressions of Cytoskeleton Proteins}

In our study, altered proteins involved in metabolic process occupied major share. Of which, glycolytic/gluconeogenesis enzymes including alpha-enolase (ENO1), gamma-enolase (ENO2), triosephosphate isomerase (TPI1) and phosphoglycerate kinase 1 (PGK1) were found to be down-regulated in response to tachyplesin I treatment. In addition, tachyplesin I treatment on U251 gliomaspheres changed the expression of cytoskeleton proteins. Eighteen out of 192 altered proteins induced by tachyplesin I were classified into cytoskeleton protein class in PANTHER classification system. Several cytoskeleton proteins such as spectrin beta chain, non-erythrocytic 2 (SPTBN2), keratin, type II cytoskeletal 1 (KRT1), keratin, type II cytoskeletal 2 epidermal (KRT2), keratin, type I cytoskeletal 9 (KRT9), keratin, type I cytoskeletal 10 (KRT10), vimentin (VIM), ezrin (EZR), interferon-induced GTP-binding protein Mx1 (MX1), interferon-induced GTP-binding protein Mx2 (MX2), cysteine and glycine-rich protein 1 (CSRP1), elongation factor 1-gamma (EEF1G) and tubulin beta-2B chain (TUBB2B) were down-regulated (Table 2) while neurofilament light polypeptide (NEFL), nestin (NES), kinesin-like protein KIF11 (KIF11), tropomyosin alpha-4 chain (TPM4), dystonin (DST) and LIM and cysteine-rich domains protein 1 (LMCD1) were observed with up-regulation (Table 2). To some extent, all these downstream effects of tachyplesin I contribute to its anti-tumor activity.

\section{5. tachyplesin I Reduces Expressions of Several Lysosomal Acid Hydrolases}

As shown in Figure 4A, consistent with the results of proteomic analysis, protein level of lysosomal protective protein (CTSA) was verified to be down-regulated by tachyplesin I using Western blot. Further, other family members of cathepsins, including cathepsin B (CTSB) and cathepsin D (CTSD), as well as cathepsin A (CTSA) were analyzed by PRM mass spectrometry with three technical replicates. For each protein, two unique peptides were selected and monitored for quantification. The skyline software was used to extract the peak areas (area under the curve, AUC) of six to seven strongest transition ions for each peptide (Supplementary Materials Table S5). The normalized sum AUC of all the transitions for each peptide are showed in Figure 4B, which demonstrates that two unique peptides derived from the same protein have a consistent trend, and variations among different technical replicates are small. The results of PRM analysis showed that tachyplesin I down-regulated the levels of CTSA, CTSB and CTSD, which are consistent with dimethyl labeling results. 

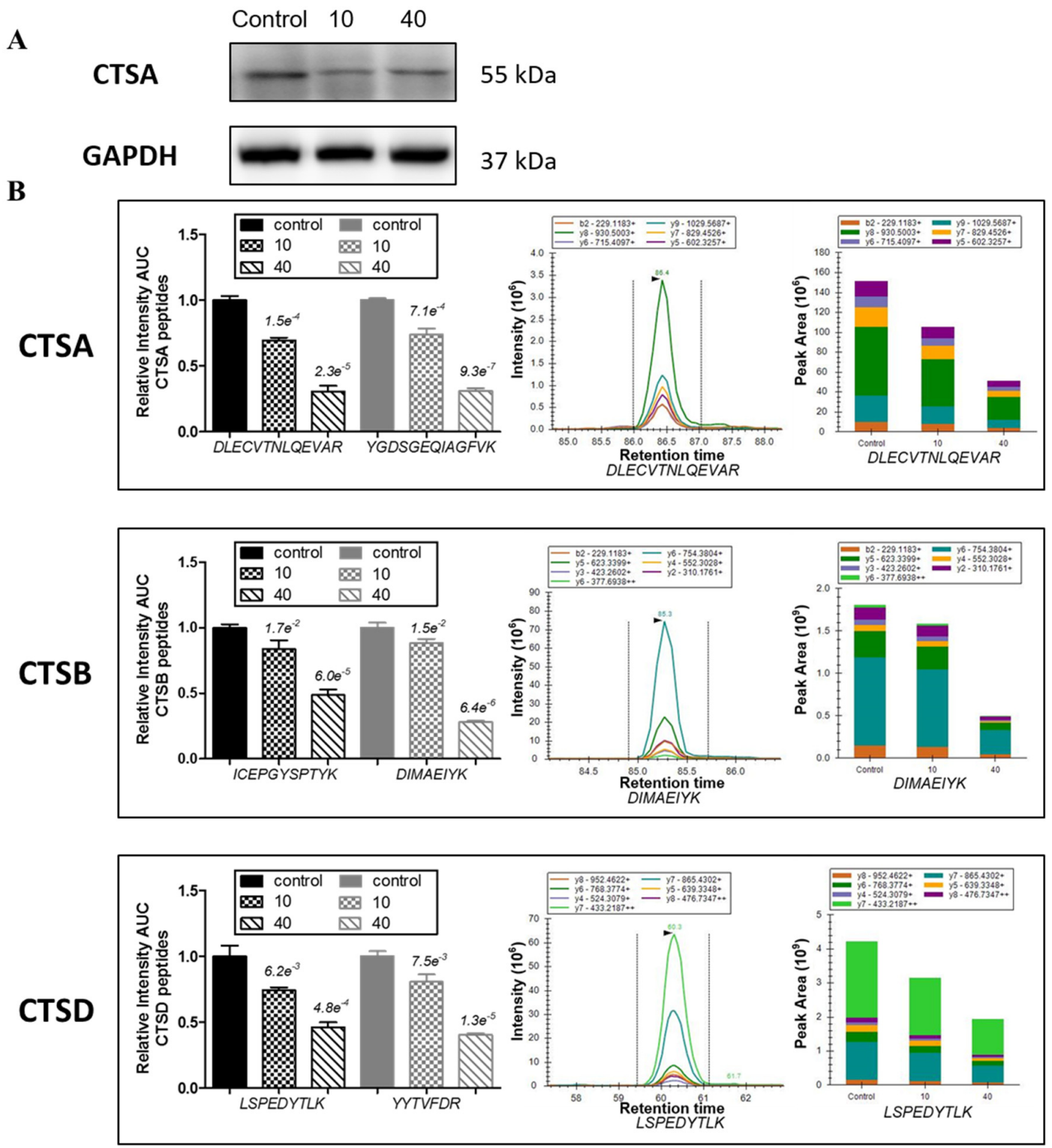

Figure 4. tachyplesin I reduces expressions of several lysosomal acid hydrolases in U251 gliomaspheres. (A) Expression of cathepsin A (CTSA) was validated by Western blot. GAPDH was used as a loading control; (B) Expressions of CTSA, cathepsin B (CTSB) and cathepsin D (CTSD) were validated by PRM mass spectrometry. The quantification for two peptides per protein in different dose groups is presented.

\subsection{Protein-Protein Interaction Network of Differentially Expressed Proteins}

Protein-protein interaction (PPI) network was established based on the total 192 differentially expressed proteins related to tachyplesin I treatment, including 26 proteins found in 2D-DIGE analysis and 166 proteins found in dimethyl labeling-based LC-MS analysis. Among them, 180 proteins could connect into a network through direct interaction or an intermediate partner at the PPI level (Figure 5A). Interestingly, DNA topoisomerase 2-alpha (TOP2A) seemed to be the crucial protein in the effects of tachyplesin I as it has the most numerous connections and forms the most complex link with other proteins in the signal network (Figure 5B). 

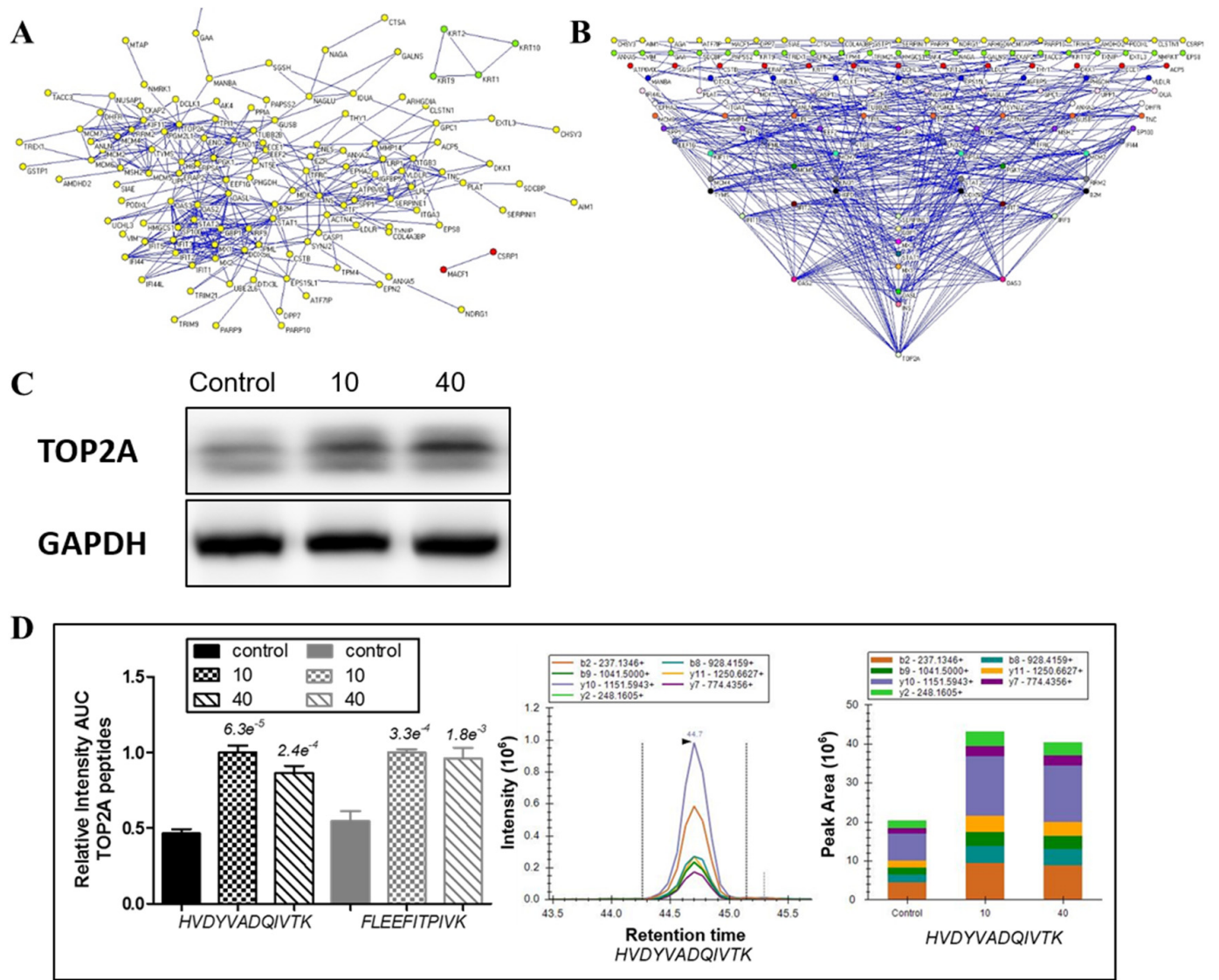

E

Overall Survival Kaplan-Meier Estimate

Disease Free Survival Kaplan-Meier Estimate

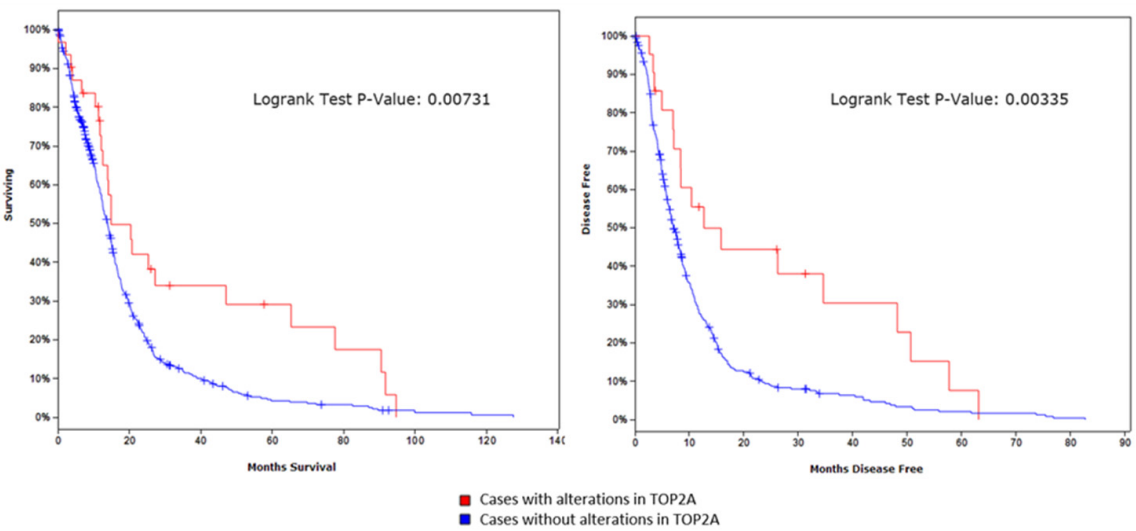

Figure 5. Role of DNA topoisomerase 2-alpha (TOP2A) in protein-protein interaction (PPI) map of tachyplesin I. (A) The constructed minimum PPI network of tachyplesin I containing 192 differentially expressed proteins found in 2D-DIGE and dimethyl labeling-based LC-MS analysis; (B) Degree distribution map of the proteins in PPI network of tachyplesin I. The proteins are shown as round dots and different colors were only related to degree in the network. TOP2A exhibited to have the biggest degree among all differentially expressed proteins; (C) Expression of TOP2A was validated by Western blot. GAPDH was used as a loading control; (D) Expression of TOP2A was validated by PRM mass spectrometry. The quantification for two peptides per protein in different dose groups is presented; (E) The overall survival (left panel) and the disease-free survival (right panel) of glioma cases with or without alterations in TOP2A. The red curves in the Kaplan-Meier plots includes cases with alterations in TOP2A, the blue curves includes cases without alterations in TOP2A. 


\subsection{Confirmation of the Involvement of TOP2A in the Effects of tachyplesin I and Correlation with Clinical Prognosis in TCGA Database}

Western blot result (Figure 5C) showed that the expression level of TOP2A was dose-dependent increased after treatment of tachyplesin I, which was consistent with the result of dimethyl labeling based LC-MS/MS analysis (Table 2). At the same time, the expression level of TOP2A was also checked by PRM analysis. As shown in Figure 5D, after tachyplesin I treatment, the expression level of TOP2A was up-regulated, which verified the data obtained from dimethyl labeling based quantification. Then, we used cBioPortal tool to analyze the relationship between the mRNA transcript level of TOP2A and clinical prognosis of GBM patients based on TCGA database to examine the effects of tachyplesin I by targeting on TOP2A. As shown in Figure 5E, patients with alterations in TOP2A at mRNA transcript level have a better prognosis compared with those without alterations in TOP2A. The analysis showed a significantly better overall and disease-free survival of patients with over-expression of TOP2A.

\section{Discussion}

More and more studies have shown that certain cationic antimicrobial peptides (AMPs), which are toxic to bacteria but not to normal mammalian cells, exhibit a broad spectrum of cytotoxic activity against cancer cells [20]. tachyplesin I, which is isolated from hemocytes of the horseshoe crab, has been identified as a member of AMPs and exhibits cytotoxic activity against cancer cells. However, it is uncertain why only some types of AMPs get kill cancer cells, while others not. Besides, whether the molecular mechanisms underlying the antitumor and antimicrobial activities are the same or not remains unclear. Through this study we aim to identify the protein targets of tachyplesin I in U251 gliomaspheres by carrying out a large-scale proteome analysis, which can help us to better understand the molecular mechanisms underlying AMPs as potential anti-glioma drugs.

In this study, gel-based 2D-DIGE and stable isotope dimethyl labeling based LC-MS/MS analysis were combined to reveal the alteration in proteome of U251 gliomaspheres treated with tachyplesin I. A total of 192 differentially expressed proteins were identified, most of which are involved in the cellular process of metabolism, especially glycolysis process, and many proteins are localized as cytoskeleton proteins and lysosomal acid hydrolases. Especially, the expression level of some proteins of interest was validated by PRM, a high-resolution method first published in 2012 and had several potential advantages over traditional approach [21]. For example, PRM spectra are highly specific as a result of all the product ions of a peptide are recorded to confirm peptide identity, while traditional MRM analysis can only monitor one transition of a precursor peptide at a time. Moreover, high-resolution of the orbitrap mass analyzer can separate co-eluted background ions, thus increasing selectivity [22].

One of the hallmarks of tumor cells is the preference of glycolysis over oxidative phosphorylation as the main source of energy. Although glycolysis yield less ATP compared to oxidative phosphorylation with the same amount of beginning materials, tumor cells overcome this disadvantage by increasing the up-take of glucose, thus facilitates a higher rate of glycolysis [23]. Studies have showed that glycolysis plays a role in the invasion activity of glioma cells and is becoming a potential drug target [24]. In this study, glycolytic/gluconeogenesis enzymes including alpha-enolase (ENO1), gamma-enolase (ENO2), triosephosphate isomerase (TPI) and phosphoglycerate kinase 1 (PGK1) were down-regulated in response to tachyplesin I treatment, indicating that tachyplesin I may disrupt the normal energy metabolism process in gliomaspheres through reduced glycolysis, thus contributing to its anti-tumor effect.

Uncontrolled and invasive proliferation is one feature of grade IV glioma, and in order to block and restrain mitotic division, cytoskeleton has been a time-honored target in cancer chemotherapy [25]. In this study, tachyplesin I treatment on U251 gliomaspheres altered the expression of 18 cytoskeleton proteins as classified by PANTHER classification system. Among them, vimentin and ezrin, which are known to be involved in the regulation of metastasis, were down-regulated under the treatment of tachyplesin I, suggesting that cytoskeleton are influenced by tachyplesin I, thus contributes to its anti-tumor activity. 
Out of 192 altered proteins, 15 are lysosomal acid hydrolases, including proteases, glycosidases, sulfatases, lipases and so on. In addition, DAVID pathway classification system revealed lysosome as the most significantly altered pathway. More and more experimental evidences suggest that tumor invasion and metastasis are associated with alterations in lysosomes and increased expression of the lysosomal proteases termed cathepsins [26]. In this study, cathepsins consist of cathepsin A, $\mathrm{B}$ and $\mathrm{D}$ were down-regulated in response to tachyplesin I treatment. Cathepsin A, also called lysosomal protective protein, is a serine carboxypeptidase implicated in autophagy. It induces tumor cell dissemination and a significant increase in cathepsin A activity in lysates of metastatic lesions of malignant tumor was observed compared to primary focus lysates [27]. Cathepsin B is a lysosomal cysteine protease of the papain family of enzymes that function as an endopeptidase and an exopeptidase [28]. Cathepsin D, an aspartic protease resides in membrane of lysosomes, is involved in autophagy and apoptosis pathways [29]. Interestingly, it has been shown that cathepsin B and D play an important role in human glioma progression and invasion [30]. The expression and enzyme activity of cathepsin B and D gradually increased in high-grade glioblastoma. Inhibition of cathepsin B or D activity attenuates extracellular matrix degradation thus reduces migration of glioma cells [31]. Our data showed that the levels of these cathepsins were significantly decreased in tachyplesin I-treated gliomaspheres compared with untreated cells. All those evidences indicate the potential of tachyplesin I as a therapeutic agent for glioma by targeting the lysosomal activity.

In further PPI analysis of differentially expressed proteins, DNA topoisomerase 2-alpha (TOP2A) was shown to be the possible critical target protein of tachyplesin I. TOP2A is a nuclear enzyme for regulation of DNA topology and replication. TOP2A was discovered to be the target of many anti-tumor drugs which had already been widely used in clinic. Previous reports have shown that DNA damage and fragmentation induced by covalent binding of TOP2A to DNA, and forced expression of TOP2A in cells triggered the apoptotic cell death [32,33]. In addition, the TOP2A level has a close relationship with the activity of these anti-tumor drugs and a high level of TOP2A is the foundation of drug susceptibility. Meanwhile, decreased level, altered phosphorylation or mutation of TOP2A could induce the loss of anti-tumor drug target and develop multiple drug resistance (MDR), which has been confirmed in atypical MDR studies with many cell lines [34,35]. Our results showed that there was an increased TOP2A level in U251 gliomaspheres treated with tachyplesin I and it suggest the possible synergistic effect with TOP2A-targeting drugs, combination of which may be more effective on targeted goals and improve chemotherapy effect.

\section{Material and Methods}

\subsection{Cell Culture and Treatment with tachyplesin I}

U251 human glioma cells were obtained from the Chinese Academy of Sciences Cell Band (Shanghai, China) and cultured in RPMI-1640 medium containing 10\% fetal bovine serum (FBS) and 100 units $/ \mathrm{mL}$ penicillin/streptomycin at $37^{\circ} \mathrm{C}$ in a humidified atmosphere with $5 \% \mathrm{CO}_{2}$. The U251 cells in the logarithmic growth phase were thoroughly dissociated to prepare single-cell suspensions. Cell suspensions were washed twice in PBS and resuspended in Neurobasal-A medium with $1 \times$ B27 plus $50 \mathrm{ng} / \mathrm{mL}$ basic fibroblast growth factor (bFGF) and $50 \mathrm{ng} / \mathrm{mL}$ epidermal growth factor (EGF). After 7 days culture, clones of different morphological types were collected. The obtained cells which exhibited certain glioma stem cell phenotypes [11] were cultured as gliomaspheres and passaged every 7 days, based on sphere size.

tachyplesin I was synthesized by Hanyu Bioengineering Company (Shenzhen, China) with a purity of $>95 \%$. Concentrations of tachyplesin I for cell exposure were determined by cell viability assay as described previously [11]. The second generation gliomaspheres were treated with 0,10 , 40 and $80 \mu \mathrm{g} / \mathrm{mL}$ of tachyplesin I for $24 \mathrm{~h}$, and then cells were centrifuged and collected. 


\subsection{CyDye Minimal Labeling of Protein Samples and 2D-DIGE Electrophoresis}

Proteins were extracted from gliomaspheres treated with $0,10,40$ and $80 \mu \mathrm{g} / \mathrm{mL}$ of tachyplesin I using the lysis buffer containing $7 \mathrm{M}$ urea, $2 \mathrm{M}$ thiourea, $4 \%(w / v)$ CHAPS and $30 \mathrm{mM}$ Tris-HCl. The concentrations of proteins were determined with the 2-D Quant kit (GE Healthcare, Piscataway, NJ, USA) according to the manufacturer's instructions. Then an equal amount $(25 \mu \mathrm{g})$ of each protein sample was minimally labeled with $\mathrm{Cy} 3$ or Cy5 fluorescent dyes (GE Healthcare) according to the manufacturer's recommended protocols and the internal standard, resulting from pooling equal aliquots of all experimental samples, was labeled with Cy2.

Six differently pooled samples (Table 4), which comprised equal amounts of Cy3- and Cy5-labeled protein samples and Cy2-labeled internal standard, were then separated by first dimension of isoelectric focusing using $24 \mathrm{~cm}$ IPG strips ( $\mathrm{pH}$ 3-11, nonlinear gradient, GE Healthcare), followed by second dimension separation into 12.5\% SDS-PAGE gels. Gels were then scanned with different channels for Cy2-, Cy3-, and Cy5-labeled proteins, using a Typhoon Trio Variable Mode Imager (GE Healthcare). The resulting 18 maps were imported into DeCyder 2D v6.5 (GE Healthcare) for statistical analysis. Each gel was separately processed by the Differential In-gel Analysis (DIA) module for spot detection, background subtraction and in-gel normalization before processed by the Biological Variation Analysis (BVA) module for spot matching and intercomparison across the six gels. Student's $t$-test was used to analyze the significance of protein spots between two groups, and one way ANOVA was subsequently used to assess the biological significance among all the experimental groups. Statistically significant spots $(p<0.05)$ with an average ratio $\geq 1.5$ or $\leq-1.5$ were chosen for protein identification.

Table 4. Labeling scheme of DIGE for U251 gliomaspheres protein.

\begin{tabular}{cccc}
\hline Gel No. & Cy2 & Cy3 & Cy5 \\
\hline Gel 01 & Standard & A1 & B2 \\
Gel 02 & Standard & B1 & C3 \\
Gel 03 & Standard & C2 & D3 \\
Gel 04 & Standard & D2 & A2 \\
Gel 05 & Standard & A3 & C1 \\
Gel 06 & Standard & B3 & D1
\end{tabular}

A: control group; B: $10 \mu \mathrm{g} / \mathrm{mL}$ dose group; C: $40 \mu \mathrm{g} / \mathrm{mL}$ dose group; $\mathrm{D}: 80 \mu \mathrm{g} / \mathrm{mL}$ dose group; 1 -3: three biological repeats in each group.

\subsection{In-Gel Digestion and Protein Identification by MALDI-TOF/TOF}

For identification of spots of interest, a gel was prepared by separating $1 \mathrm{mg}$ of unlabeled proteins pooled from all the samples. The gel was stained by Coomassie Brilliant Blue G-250 and destained by water to reveal the protein spots. After matching to the analytical DIGE gel, each spot of interest was manually excised from the gel and put into a $1.5 \mathrm{~mL}$ tube, followed by thorough decoloration with $50 \%$ acetonitrile in $25 \mathrm{mM}$ ammonium bicarbonate and dehydration in 100\% acetonitrile. Then each gel piece was digested overnight at $37^{\circ} \mathrm{C}$ by trypsin in $25 \mathrm{mM}$ ammonium bicarbonate buffer. Peptides were extracted from each gel piece, desalted, and identified by an UltrafleXtreme MALDI-TOF/TOF mass spectrometer (Bruker Daltonics, Billerica, MA, USA) according to previously described [20].

\subsection{Dimethyl Labeling of Protein Samples}

Cells were lysed with a lysis buffer containing 4\% SDS, $100 \mathrm{mM}$ Tris, $\mathrm{pH} 8.0$ and $1 \times$ protease inhibitor cocktail (Roche, Indianapolis, IN, USA). Protein concentrations were determined using a Pierce BCA Protein Assay Kit (Thermo Fisher Scientific, Waltham, MS, USA). One milligram protein from each sample was reduced with $5 \mathrm{mM}$ dithiothreitol, alkylated with $15 \mathrm{mM}$ iodoacetamide, and precipitated by methanol and chloroform [36]. The resulting pellets were resuspended in lysis buffer containing $8 \mathrm{M}$ urea, $0.1 \mathrm{M}$ Tris- $\mathrm{HCl}, \mathrm{pH} 8.5$ and the concentration of urea was diluted to below $2 \mathrm{M}$ before overnight digestion with trypsin (Promega, Madison, WI, USA). 
Dimethyl labeling was performed on-column according to Nature Protocols by Boersema P.J. et al. [37] with minor modifications. Briefly, acidified peptide samples were loaded into SepPak columns (Waters, Milford, MA, USA) after the columns were activated by methanol, $80 \%$ acetonitrile in $0.1 \%$ trifluoroacetic acid (TFA), and conditioned by $0.1 \%$ TFA. After desalting, the samples were labeled separately by passing the columns with $\mathrm{CH}_{2} \mathrm{O}$ and $\mathrm{NaBH}_{3} \mathrm{CN}$ (light), $\mathrm{CD}_{2} \mathrm{O}$ and $\mathrm{NaBH}_{3} \mathrm{CN}$ (medium) and $\mathrm{CD}_{2} \mathrm{O}$ and $\mathrm{NaBD}_{3} \mathrm{CN}$ (heavy) (Sigma-Aldrich, St. Louis, MO, USA) for $20 \mathrm{~min}$ at room temperature. Labeling scheme was shown in Table 5. Then the differentially labeled samples were eluted from the columns, mixed and dried by Speedvac (Labconco, Kansas, MO, USA).

Table 5. Dimethyl-labeling scheme for U251 gliomaspheres protein.

\begin{tabular}{ccc}
\hline Samples & Forward & Reverse \\
\hline control group & Heavy $(\mathrm{H})$ & Light $(\mathrm{L})$ \\
$10 \mu \mathrm{g} / \mathrm{mL}$ dose group & Light $(\mathrm{L})$ & Medium $(\mathrm{M})$ \\
$40 \mu \mathrm{g} / \mathrm{mL}$ dose group & Medium $(\mathrm{M})$ & Heavy $(\mathrm{H})$ \\
\hline
\end{tabular}

\subsection{High $\mathrm{pH}$ Fractionation of Peptides and LC-MS/MS Analysis by Obitrap}

The dimethyl-labeled sample was resuspended in 1\% formic acid (FA), loaded into SepPak column, and fractionated into five fractions by eluting the peptides with 3\%,6\%, 9\%, 15\% and $80 \%$ ( $\mathrm{vol} / \mathrm{vol}$ ) acetonitrile in $5 \mathrm{mM}$ ammonium formate ( $\mathrm{pH} 10.0)$, sequentially. After lyophilization in Speedvac, samples were resuspended in $0.1 \%$ FA and analyzed by a Q-Exactive orbitrap mass spectrometer (Thermo Fisher Scientific) coupled to an Easy-nLC 1000 (Thermo Fisher Scientific) ultrahigh pressure liquid chromatography (UHPLC). The LC separation system consisted of a trap column $(100 \mu \mathrm{m}$ i.d. $\times 4 \mathrm{~cm})$ and an analytical column $(75 \mu \mathrm{m}$ i.d. $\times 20 \mathrm{~cm})$ both packed with $3 \mu \mathrm{m} /$ $120 \AA$ A 18 resins (Dr. Maisch HPLC GmbH, Ammerbuch, Germany). The eluting buffers were $0.1 \%$ FA in $\mathrm{H}_{2} \mathrm{O}$ (buffer A) and $0.1 \%$ FA in $99.9 \% \mathrm{ACN}$ (buffer B). The peptides were first loaded onto the trap column and then separated by the analytical column with 50 min gradient from $7 \%$ to $22 \%$ buffer B followed by 10 min gradient from $22 \%$ to $35 \%$ buffer B at a flow rate of $300 \mathrm{~nL} / \mathrm{min}$. MS data was acquired in data dependent acquisition (DDA) mode. Survey full scan MS spectra $(m / z 350-1550)$ were acquired in the Orbitrap with resolution of 70,000, target automatic gain control (AGC) value of $3 \times 10^{6}$, and maximum injection time of $100 \mathrm{~ms}$. Dynamic exclusion for scanned presursors was employed for $60 \mathrm{~s}$. After each MS scan, the 10 most intense precursor ions $(z \geq 2)$ were sequentially isolated and fragmented by higher-energy collisional dissociation (HCD) using normalized energy $27 \%$ with an AGC target of $1 \times 10^{5}$ and a maxima injection time of $50 \mathrm{~ms}$ at 17,500 resolution.

Raw data were searched through UniProt Homo sapiens protein database containing 70,076 sequence entries via Sequest HT algorithm with the following parameters: two missed cleavage sites by trypsin, $10 \mathrm{ppm}$ mass tolerance for precursors, 0.02 Da mass tolerance for fragments, and carbamidomethylation $(+57.021 \mathrm{Da})$ of cysteineas static modifications. Moreover, the following dynamic modifications were also set: oxidation of methionine $(+15.995 \mathrm{Da})$, deamidation of asparagine or glutarnine $(+0.984 \mathrm{Da})$, and dimethylation for light-labeled $(+28.031 \mathrm{Da})$ or medium-labeled $(+32.056 \mathrm{Da})$ or heavy-labeled $(+36.076 \mathrm{Da})$ lysine, and $N$-terminus. All the identified peptides were filtered by FDR $<0.01$ as reliable identification. Protein Discoverer was used for relative quantification. Differentially expressed proteins were considered for ratios $\leq 0.5$ (down-regulated) and $\geq 2$ (up-regulated).

\subsection{Bioinformatic Analysis}

The function reports of the candidate proteins whose expression was altered in U251 gliomaspheres due to the effect of tachyplesin I treatment were obtained from the UniProt database (http://www.uniprot.org/) and the protein list of UniProt IDs was input into the PANTHER classification system (http:/ / pantherdb.org/) for GO analysis according to their molecular functions 
and biological processes. The relevant signaling pathways highly associated with the effect of tachyplesin I treatment on U251 gliomaspheres were identified using DAVID analysis (https:/ / david. ncifcrf.gov/). The protein-protein interaction network of all the differentially expressed proteins was established using String (http://string-db.org/), and then the data was exported as net file and imported into pajek software for degree based partition of the proteins in the network. The correlation of the possible key proteins involved in the effects of tachyplesin I in our proteomic analysis with its mRNA transcript level and clinical prognosis in GBM patients based on per TCGA data was analyzed by cBioPortal tools (http://www.cbioportal.org/) [38].

\subsection{Parallel Reaction Monitoring (PRM) Mass Spectrometry}

We applied PRM to validate the major protein changes observed in the dimethyl labeling analyses. Proteins were extracted from another batch of differently treated U251 gliomaspheres (biological replicate) and digested to peptides. These unlabeled peptides were fractionated and identified as described above with only difference in database searching (no dimethylation as dynamic modifications). For PRM analysis, $2 \mu \mathrm{g}$ of non-fractionated peptides from each group were separated using the same LC system. Linear gradient ranging from $4 \%$ to $35 \%$ buffer B over 60 min was used. For each target protein, two unique precursor peptide ions were monitored in the inclusion list. The settings for MS full scan were the same as in the DDA mode with only different in $m / z$ scan range (300-900). The following MS/MS PRM scan parameters were set: orbitrap resolution of 35,000, AGC target value of $5 \times 10^{5}$, auto maximum IT, isolation window of $2 \mathrm{~m} / z$, HCD collision energy of 27 , and starting mass of $m / z$ 110. The PRM raw files were analysed using Skyline [39] to extract the peak areas of six to seven most intense transitions for each peptide. Then the data was imported to GraphPad for statistical analysis. Differences between two groups were analyzed by the Student's $t$-test and statistical significance was considered when $p<0.05$.

\subsection{Western Blot Assay}

Total proteins were extracted from different groups of U251 gliomaspheres with the same treatment as described in the DIGE analysis, and protein concentrations were quantified by BCA kit. Western blot procedures were carried out as we previously described [40], with minor modifications. Namely, after boiling for 5 min with loading buffer, the same amount of proteins from each groups were separated by SDS-PAGE and transferred onto PVDF membranes. The membranes were incubated with mouse monoclonal anti-ECE-1 antibody (sc-376017, Santa Cruz, CA, USA), mouse monoclonal anti-alpha-enolase (sc-101513, Santa Cruz, CA, USA), mouse monoclonal anti-cathepsin A (sc-73766, Santa Cruz, CA, USA) and mouse monoclonal anti-GAPDH (sc-32233, Santa Cruz, CA, USA) at 1:500 dilution. The immunoblots were developed by incubation with goat anti-mouse IgG-HRP (sc-2005, Santa Cruz, CA, USA) as the secondary antibody followed by ECL detection (GE Healthcare).

\section{Conclusions}

In our study, we combined a gel-based 2D-DIGE approach and a dimethyl labeling LC-MS-based shotgun proteomic strategy to identify the proteome expression alterations in U251 gliomaspheres treated with different doses of tachyplesin I. Our results demonstrate complementary advantages of these two techniques. We show that tachyplesin I alters the cellular metabolism, especially glycolysis process and changes the expression of several cytoskeleton proteins and lysosomal acid hydrolases. Moreover, the important role of DNA topoisomerase 2-alpha (TOP2A) in the signal cascades of tachyplesin I was suggested. Further, parallel reaction monitoring (PRM) mass spectrometry confirmed that the major protein of lysosomal acid hydrolases including cathepsin A, cathepsin B and cathepsin D were down-regulated and the possible target-related protein TOP2A was up-regulated by tachyplesin I treatment. In conclusion, we propose that tachyplesin I may down-regulate cathepsins in lysome and up-regulate TOP2A to inhibit migration and promote apoptosis in glioma, thus contributing to its anti-tumor activity. Further work including functional analyses is needed to elucidate the mode of 
action of tachyplesin I in tumor cells. As far as we know, there is no previous report that reveals the effect of tachyplesin I on proteome of gliomaspheres and our findings imply that tachyplesin I could serve as a promising candidate in the combined therapy against glioma.

Supplementary Materials: The following are available online at www.mdpi.com/1660-3397/15/1/20/s1, Table S1: Total identified peptides information in the forward dimethyl labeling experiment, Table S2: Total identified peptides information in the reverse dimethyl labeling experiment, Table S3: Total identified proteins in the forward dimethyl labeling experiment, Table S4: Total identified proteins in the reverse dimethyl labeling experiment, Table S5: Transitions obtained in Parallel Reaction Monitoring (PRM).

Acknowledgments: This work was supported by the Shenzhen Science and Technology Development Fund Project (No. JCYJ20130331151022276 and GGJS20130331152344401), GDUHTP (2011 and 2013), GDPRSFS (2012), the Project of Guangdong Science and Technology Plan (No. 2014A020217021) and the National Natural Science Foundation of China (No. 31272474).

Author Contributions: Gang Jin conceived and designed the experiments; Xuan Li performed the experiments and wrote the paper; Jianguo Dai contributed reagents/materials/analysis tools and revised the manuscript; Yongjun Tang analyzed the data; and Lulu Li cultured the cells.

Conflicts of Interest: The authors declare no conflict of interest.

\section{References}

1. Alifieris, C.; Trafalis, D.T. Glioblastoma multiforme: Pathogenesis and treatment. Pharmacol. Ther. 2015, 152, 63-82. [CrossRef] [PubMed]

2. Stopschinski, B.E.; Beier, C.P.; Beier, D. Glioblastoma cancer stem cells-From concept to clinical application. Cancer Lett. 2013, 338, 32-40. [CrossRef] [PubMed]

3. Singh, S.K.; Hawkins, C.; Clarke, I.D.; Squire, J.A.; Bayani, J.; Hide, T.; Henkelman, R.M.; Cusimano, M.D.; Dirks, P.B. Identification of human brain tumour initiating cells. Nature 2004, 432, 396-401. [CrossRef] [PubMed]

4. Schonberg, D.L.; Miller, T.E.; Wu, Q.; Flavahan, W.A.; Das, N.K.; Hale, J.S.; Hubert, C.G.; Mack, S.C.; Jarrar, A.M.; Karl, R.T.; et al. Preferential iron trafficking characterizes glioblastoma stem-like cells. Cancer Cell 2015, 28, 441-455. [CrossRef] [PubMed]

5. Pointer, K.B.; Clark, P.A.; Zorniak, M.; Alrfaei, B.M.; Kuo, J.S. Glioblastoma cancer stem cells: Biomarker and therapeutic advances. Neurochem. Int. 2014, 71, 1-7. [CrossRef] [PubMed]

6. Bao, S.; Wu, Q.; Sathornsumetee, S.; Hao, Y.; Li, Z.; Hjelmeland, A.B.; Shi, Q.; McLendon, R.E.; Bigner, D.D.; Rich, J.N. Stem cell-like glioma cells promote tumor angiogenesis through vascular endothelial growth factor. Cancer Res. 2006, 66, 7843-7848. [CrossRef] [PubMed]

7. Kim, J.B. Three-dimensional tissue culture models in cancer biology. Semin. Cancer Biol. 2005, 15, 365-377. [CrossRef] [PubMed]

8. Pampaloni, F.; Reynaud, E.G.; Stelzer, E.H. The third dimension bridges the gap between cell culture and live tissue. Nat. Rev. Mol. Cell Biol. 2007, 8, 839-845. [CrossRef] [PubMed]

9. Kong, B.H.; Park, N.R.; Shim, J.K.; Kim, B.K.; Shin, H.J.; Lee, J.H.; Huh, Y.M.; Lee, S.J.; Kim, S.H.; Kim, E.H.; et al. Isolation of glioma cancer stem cells in relation to histological grades in glioma specimens. Childs Nerv. Syst. 2013, 29, 217-229. [CrossRef] [PubMed]

10. Zhang, Q.B.; Ji, X.Y.; Huang, Q.; Dong, J.; Zhu, Y.D.; Lan, Q. Differentiation profile of brain tumor stem cells: A comparative study with neural stem cells. Cell Res. 2006, 16, 909-915. [CrossRef] [PubMed]

11. Ding, H.; Jin, G.; Zhang, L.; Dai, J.; Dang, J.; Han, Y. Effects of tachyplesin I on human U251 glioma stem cells. Mol. Med. Rep. 2015, 11, 2953-2958. [PubMed]

12. Nakamura, T.; Furunaka, H.; Miyata, T.; Tokunaga, F.; Muta, T.; Iwanaga, S.; Niwa, M.; Takao, T.; Shimonishi, Y. Tachyplesin, a class of antimicrobial peptide from the hemocytes of the horseshoe crab (Tachypleus tridentatus). Isolation and chemical structure. J. Biol. Chem. 1988, 263, 16709-16713. [PubMed]

13. Rao, A.G. Conformation and antimicrobial activity of linear derivatives of tachyplesin lacking disulfide bonds. Arch. Biochem. Biophys. 1999, 361, 127-134. [CrossRef] [PubMed]

14. Chen, Y.; Xu, X.; Hong, S.; Chen, J.; Liu, N.; Underhill, C.B.; Creswell, K.; Zhang, L. RGD-tachyplesin Inhibits tumor growth. Cancer Res. 2001, 61, 2434-2438. [PubMed]

15. Li, Q.F.; Ou-Yang, G.L.; Peng, X.X.; Hong, S.G. Effects of tachyplesin on the regulation of cell cycle in human hepatocarcinoma SMMC-7721 cells. World J. Gastroenterol. 2003, 9, 454-458. [CrossRef] [PubMed] 
16. Chen, J.; Xu, X.M.; Underhill, C.B.; Yang, S.; Wang, L.; Chen, Y.; Hong, S.; Creswell, K.; Zhang, L. Tachyplesin activates the classic complement pathway to kill tumor cells. Cancer Res. 2005, 65, 4614-4622. [CrossRef] [PubMed]

17. Ouyang, G.L.; Li, Q.F.; Peng, X.X.; Liu, Q.R.; Hong, S.G. Effects of tachyplesin on proliferation and differentiation of human hepatocellular carcinoma SMMC-7721 cells. World J. Gastroenterol. 2002, 8, 1053-1058. [CrossRef] [PubMed]

18. Hoskin, D.W.; Ramamoorthy, A. Studies on anticancer activities of antimicrobial peptides. Biochim. Biophys. Acta 2008, 1778, 357-375. [CrossRef] [PubMed]

19. Baggerman, G.; Vierstraete, E.; De Loof, A.; Schoofs, L. Gel-based versus gel-free proteomics: A review. Comb. Chem. High Throughput Screen. 2005, 8, 669-677. [CrossRef] [PubMed]

20. Huang, P.; Ren, X.; Huang, Z.; Yang, X.; Hong, W.; Zhang, Y.; Zhang, H.; Liu, W.; Huang, H.; Huang, X.; et al. Serum proteomic analysis reveals potential serum biomarkers for occupational medicamentosa-like dermatitis caused by trichloroethylene. Toxicol. Lett. 2014, 229, 101-110. [CrossRef] [PubMed]

21. Peterson, A.C.; Russell, J.D.; Bailey, D.J.; Westphall, M.S.; Coon, J.J. Parallel reaction monitoring for high resolution and high mass accuracy quantitative, targeted proteomics. Mol. Cell. Proteom. 2012, 11, 1475-1488. [CrossRef] [PubMed]

22. Thomas, S.N.; Harlan, R.; Chen, J.; Aiyetan, P.; Liu, Y.; Sokoll, L.J.; Aebersold, R.; Chan, D.W.; Zhang, H. Multiplexed targeted mass spectrometry-based assays for the quantification of N-linked glycosite-containing peptides in serum. Anal. Chem. 2015, 87, 10830-10838. [CrossRef] [PubMed]

23. Ganapathy-Kanniappan, S.; Geschwind, J.F. Tumor glycolysis as a target for cancer therapy: Progress and prospects. Mol. Cancer 2013, 12, 152. [CrossRef] [PubMed]

24. Ramao, A.; Gimenez, M.; Laure, H.J.; Izumi, C.; Vida, R.C.; Oba-Shinjo, S.; Marie, S.K.; Rosa, J.C. Changes in the expression of proteins associated with aerobic glycolysis and cell migration are involved in tumorigenic ability of two glioma cell lines. Proteome Sci. 2012, 10, 53. [CrossRef] [PubMed]

25. Katsetos, C.D.; Reginato, M.J.; Baas, P.W.; D’Agostino, L.; Legido, A.; Tuszyn Ski, J.A.; Draberova, E.; Draber, P. Emerging microtubule targets in glioma therapy. Semin. Pediatr. Neurol. 2015, 22, 49-72. [CrossRef] [PubMed]

26. Fehrenbacher, N.; Jaattela, M. Lysosomes as targets for cancer therapy. Cancer Res. 2005, 65, $2993-2995$. [PubMed]

27. Kozlowski, L.; Wojtukiewicz, M.Z.; Ostrowska, H. Cathepsin A activity in primary and metastatic human melanocytic tumors. Arch. Dermatol. Res. 2000, 292, 68-71. [CrossRef] [PubMed]

28. Aggarwal, N.; Sloane, B.F. Cathepsin B: Multiple roles in cancer. Proteom. Clin. Appl. 2014, 8, $427-437$. [CrossRef] [PubMed]

29. Nicotra, G.; Castino, R.; Follo, C.; Peracchio, C.; Valente, G.; Isidoro, C. The dilemma: Does tissue expression of cathepsin D reflect tumor malignancy? The question: Does the assay truly mirror cathepsin D mis-function in the tumor? Cancer Biomark. 2010, 7, 47-64. [PubMed]

30. Tan, G.J.; Peng, Z.K.; Lu, J.P.; Tang, F.Q. Cathepsins mediate tumor metastasis. World J. Biol. Chem. 2013, 4, 91-101. [PubMed]

31. Liu, Y.; Zhou, Y.; Zhu, K. Inhibition of glioma cell lysosome exocytosis inhibits glioma invasion. PLoS ONE 2012, 7, e45910. [CrossRef] [PubMed]

32. Vassetzky, Y.S.; Alghisi, G.C.; Gasser, S.M. DNA topoisomerase II mutations and resistance to anti-tumor drugs. Bioessays 1995, 17, 767-774. [CrossRef] [PubMed]

33. McPherson, J.P.; Goldenberg, G.J. Induction of apoptosis by deregulated expression of DNA topoisomerase IIalpha. Cancer Res. 1998, 58, 4519-4524. [PubMed]

34. McPherson, J.P.; Brown, G.A.; Goldenberg, G.J. Characterization of a DNA topoisomerase IIalpha gene rearrangement in adriamycin-resistant P388 leukemia: Expression of a fusion messenger RNA transcript encoding topoisomerase iialpha and the retinoic acid receptor alpha locus. Cancer Res. 1993, 53, 5885-5889. [PubMed]

35. Withoff, S.; De Jong, S.; De Vries, E.G.; Mulder, N.H. Human DNA topoisomerase II: Biochemistry and role in chemotherapy resistance (review). Anticancer Res. 1996, 16, 1867-1880. [PubMed]

36. Wessel, D.; Flugge, U.I. A method for the quantitative recovery of protein in dilute solution in the presence of detergents and lipids. Anal. Biochem. 1984, 138, 141-143. [CrossRef] 
37. Boersema, P.J.; Raijmakers, R.; Lemeer, S.; Mohammed, S.; Heck, A.J. Multiplex peptide stable isotope dimethyl labeling for quantitative proteomics. Nat. Protoc. 2009, 4, 484-494. [CrossRef] [PubMed]

38. Gao, J.; Aksoy, B.A.; Dogrusoz, U.; Dresdner, G.; Gross, B.; Sumer, S.O.; Sun, Y.; Jacobsen, A.; Sinha, R.; Larsson, E.; et al. Integrative analysis of complex cancer genomics and clinical profiles using the cbioportal. Sci. Signal. 2013. [CrossRef] [PubMed]

39. MacLean, B.; Tomazela, D.M.; Shulman, N.; Chambers, M.; Finney, G.L.; Frewen, B.; Kern, R.; Tabb, D.L.; Liebler, D.C.; MacCoss, M.J. Skyline: An open source document editor for creating and analyzing targeted proteomics experiments. Bioinformatics 2010, 26, 966-968. [CrossRef] [PubMed]

40. Li, X.; Li, X.; Zhu, Z.; Huang, P.; Zhuang, Z.; Liu, J.; Gao, W.; Liu, Y.; Huang, H. Poly(ADP-ribose) glycohydrolase (PARG) silencing suppresses benzo(a)pyrene induced cell transformation. PLoS ONE 2016, 11, e0151172. [CrossRef] [PubMed]

(C) 2017 by the authors; licensee MDPI, Basel, Switzerland. This article is an open access article distributed under the terms and conditions of the Creative Commons Attribution (CC-BY) license (http://creativecommons.org/licenses/by/4.0/). 